\title{
Gut Microbiota in Multiple Sclerosis and Experimental Autoimmune Encephalomyelitis: Current Applications and Future Perspectives
}

\author{
Fengna Chu $\mathbb{D},{ }^{1}$ Mingchao Shi $\mathbb{D},{ }^{1}$ Yue Lang, ${ }^{1}$ Donghui Shen $\mathbb{D},{ }^{1}$ Tao Jin $\mathbb{D},{ }^{1}$ Jie Zhu $\mathbb{D},{ }^{1,2}$ \\ and Li Cui $\left.{ }^{1}\right)^{1}$ \\ ${ }^{1}$ Department of Neurology and Neuroscience Center, The First Hospital of Jilin University, Changchun, Jilin Province, China \\ ${ }^{2}$ Department of Neurobiology, Care Sciences \& Society, Division of Neurodegeneration, Karolinska Institutet and Karolinska \\ University Hospital Huddinge, Stockholm, Sweden
}

Correspondence should be addressed to Jie Zhu; jie.zhu@ki.se and Li Cui; chuili1967@126.com

Received 25 October 2017; Revised 22 February 2018; Accepted 4 March 2018; Published 2 April 2018

Academic Editor: Ronald Gladue

Copyright (C) 2018 Fengna Chu et al. This is an open access article distributed under the Creative Commons Attribution License, which permits unrestricted use, distribution, and reproduction in any medium, provided the original work is properly cited.

\begin{abstract}
The gut environment and gut microbiome dysbiosis have been demonstrated to significantly influence a range of disorders in humans, including obesity, diabetes, rheumatoid arthritis, and multiple sclerosis (MS). MS is an autoimmune disease affecting the central nervous system (CNS). The etiology of MS is not clear, and it should involve both genetic and extrinsic factors. The extrinsic factors responsible for predisposition to MS remain elusive. Recent studies on MS and its animal model, experimental autoimmune encephalomyelitis (EAE), have found that gastrointestinal microbiota may play an important role in the pathogenesis of MS/EAE. Thus, gut microbiome adjustment may be a future direction of treatment in MS. In this review, we discuss the characteristics of the gut microbiota, the connection between the brain and the gut, and the changes in gut microbiota in MS/EAE, and we explore the possibility of applying microbiota therapies in patients with MS.
\end{abstract}

\section{Introduction}

Multiple sclerosis (MS) is an autoimmune central nervous system (CNS) disease, and experimental autoimmune encephalomyelitis (EAE) is an animal model of MS. The etiology and pathogenesis of MS and EAE remain unknown. Recently, studies have focused on the microbes that colonize the skin and mucosal surfaces and mainly those that may be found in the gastrointestinal (GI) tract [1-3]. It has been shown that an imbalance in the gut microbiota, called "dysbiosis," is associated with various diseases, ranging from intestinal diseases, like colorectal cancer, irritable bowel syndrome, and inflammatory bowel disease (IBD) [4], to other systemic diseases such as obesity [5], malnutrition [6], diabetes, metabolic syndrome, and rheumatoid arthritis (RA) $[7,8]$. In the field of neurology, attention is also focused on the role of the gut microbiota in CNS diseases, such as Alzheimer's disease and Parkinson's disease (PD) $[9,10]$.
Many recent studies have also found that the gut microbiota plays an important role in MS; this will help us find a new way to treat MS or prevent MS relapse.

\section{The Microbiome}

Human normal microorganisms consist of bacteria, microeukaryotes, fungi, yeast, archaea, helminths, protozoa, parasites, and viruses/phages, which are mainly distributed in the internal cavity of the body, such as respiratory tract, digestive tract, urogenital tract, and body surface, forming four microecosystems, with more than $95 \%$ of them located in the large intestine $[11,12]$. All microbes including bacteria, archaea, fungi, and viruses exist in an ecosystem/habitat called microbiota, and the collective genomic, protein, or metabolite content of all the microbes in a given ecosystem/ habitat called microbiome, for example, the microbial community, in the gut is called gut microbiota or gut flora [13]. 
There are about $10^{14}$ different populations of microorganisms in the human intestinal tract, which are at least 100 times larger than the number of human genes in the body, and their total weight is approximately $2 \mathrm{~kg}[14,15]$. Such a large number of intestinal microbes and hosts have evolved over a long period of time and have become an inseparable part of the host and play an important role in maintaining the body healthy. Because of the different physiological state of the human gastrointestinal tract, there are certain differences in the species and distribution of the bacteria, and even in the intestinal and intestinal mucus layers, the microbes is different. The exact species of microbe populations has not yet been determined. However, in recent years, the Metagenomics of the Human Intestinal Tract and the Human Microbiome Project have provided the most integrated view of human-associated microbes, and Hugon et al. list 2172 species isolated in humans, which they classified into 12 different phyla, with $93.5 \%$ of them belonging to the Proteobacteria, Firmicutes, Actinobacteria, and Bacteroidetes phyla $[16,17]$, and a healthy gut contains large fractions of the phyla Firmicutes and Bacteroidetes, including the genera Prevotella, Bacteroides, and Ruminococcus, followed by Verrucomicrobia and Actinobacteria but contains a low number of Proteobacteria phyla members [18]. The colonization of the human gut begins at birth and becomes relatively stable in adulthood. Different ethnicities should have different microbiomes, and the human gut microbiota does not remain constant, as it is affected by numerous factors [19].

\subsection{Formation of Gut Microbiota and Influencing Factors.}

After birth, microbes rapidly colonize the sterile neonatal GI tract, and the microbiota composition partially depends on the delivery mode and whether breast-feeding is done [20-22]. It has been hypothesized that the different components of the gut microbiota after birth may have an impact on disease in the future [23]; research has found that a caesarean delivery and formula-feeding are associated with high incidences of infection and allergy diseases [24, 25]. One to 2.5 years after birth, the composition, diversity, and function of the infant microbiome gradually develops to resemble that of adults [26, 27]; in adulthood, most of the bacteria in the body will remain in a relatively stable state, but to the end of the life, the diversity of flora composition will decline and the ratio of Bacteroidetes/Firmicutes will increases; however, the human microbiota displays a remarkable degree of variation within and between individuals [28].

Recent evidence has shown that the adult microbiome is not as stable as previously believed, and there are many important endogenous and exogenous factors for the composition of the intestinal microbial community: (1) Genetic factors: There is an obvious adaptive relationship between host gene composition and bacterial gene composition. The bacteria can synthesize metabolites on the basis of genetic composition. These metabolites interact with each other, maintaining a stable balance between the gut microbiota and the surrounding environment. Even when twins and mother-daughter pairs had lived apart for many years, but they still have more similar microbiota compositions, suggesting that the gut microbiota may be influenced by genetics factors [29-31]. (2) Sex: The gut microbiota and sex hormone have been reported to influence each other, and research has found that males exhibited increased abundance of Bacteroides and Prevotella compared with females [32], and sex differences in the microbiome parallel immune, metabolic changes, it is important in risk and resilience of the disease throughout the lifespan [33, 34]. New studies in mice have found that adoptive transferred male microbiota to recipient females can result in elevated testosterone and metabolomic changes and delay the onset and lessen the severity of disease, which demonstrated that the female-biased risk for autoimmune disorders is significantly impacted by sex differences in the gut microbiome $[35,36]$. (3) Diet: Dietary habits and food types can influence microbial composition [37-40]. (4) Drugs: Antibiotic and other drugs can easily affect the components of the microbiome [41, 42]. (5) Others: Other implicated factors include lifestyle, illness, smoking, drug addiction, place of residence, and the climate $[43,44]$.

2.2. Normal Function of the Gut Microbiota. An intimate mutualistic relationship between the gut microbiota and the host has been developed following thousands of years, and the gut microbes have become either harmless or beneficial to the host, maintaining the balance of the systemic and local immune systems. The human gut microbiota can synthesize and secrete essential vitamins to support immune regulation, endothelial growth, and the development of the CNS. Lactic acid bacteria can produce vitamin B12 that cannot be synthesized by other animals, fungi, or plants; Bifidobacteria are the main producers for folate, which is involved in DNA synthesis and DNA repair; other vitamins, including vitamin $\mathrm{K}$, nicotinic acid, biotin, riboflavin, pantothenic acid, pyridoxine, and thiamine can also be synthesized by the human gut microbiota [45-48].

The beneficial effects of the gut microbiota on host metabolism are often considered to be mediated by short-chain fatty acids (SCFAs). These SCFAs can be absorbed in the GI tract by epithelial cells and be involved in the regulation of cellular processes like cytotaxis, proliferation, differentiation, and apoptosis [49].

Normal flora can systemically and locally stimulate the development of innate and adaptive immune systems and is required for normal immune system maturation, including gut-associated lymphoid tissue (GALT) development.

The enteric nervous system (ENS) is one of the main divisions of the autonomic nervous system and regulates the functions of the gastrointestinal tract, which has been described as a "second brain" [50]. ENS controls the motility, exocrine and endocrine secretions, and microcirculation of the gastrointestinal tract; it is also involved in regulating immune and inflammatory processes $[51,52]$.

2.3. Connection between Brain and Gut. At the end of the 19th century, the American scientist Gershon first described the concept of gut-brain connection [50]. Over the past decade, a large number of animal and preclinical studies have proven that the gut microbiota is involved in regulating physiological processes in humans, such as host metabolism 


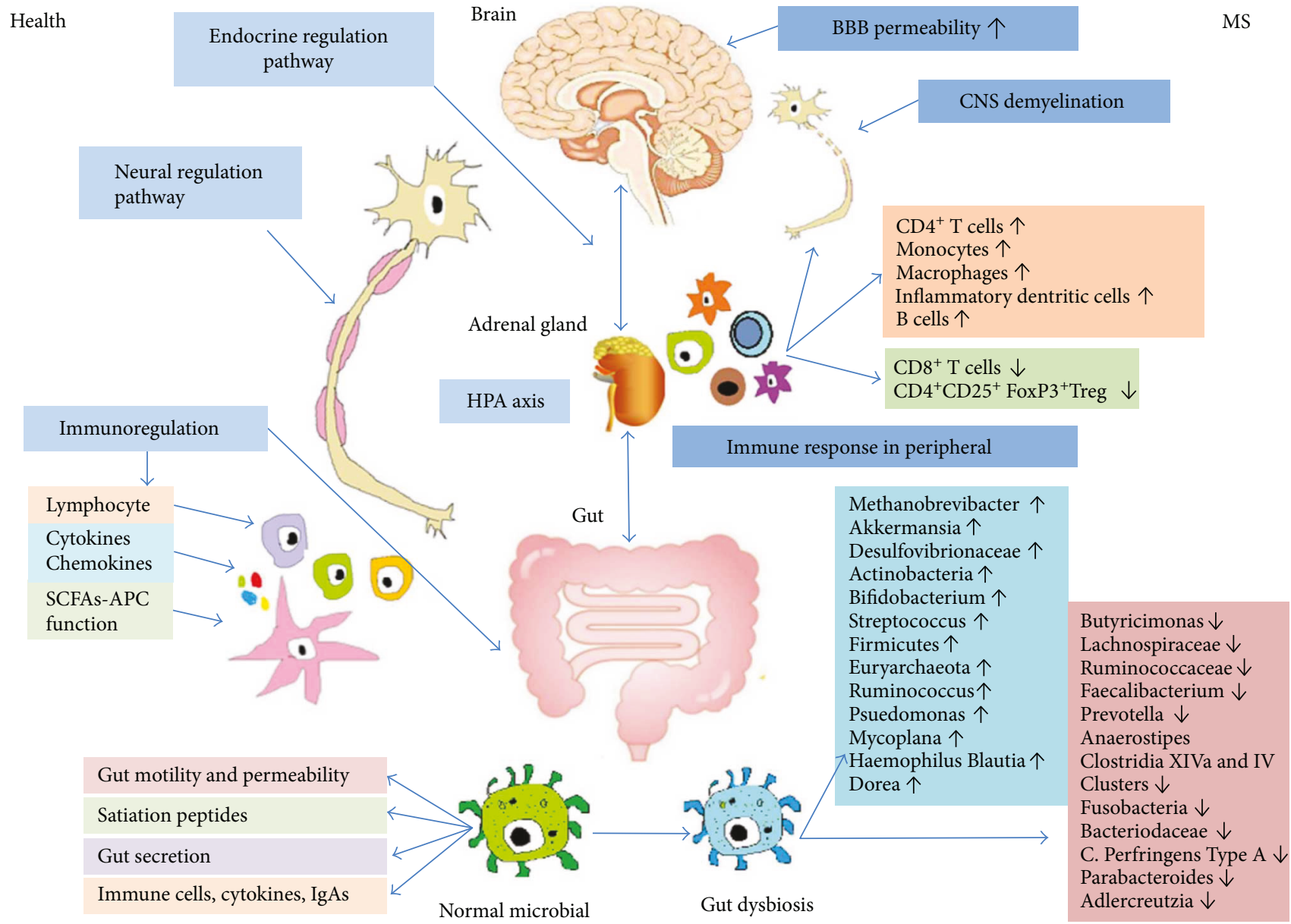

FIGURE 1: The role of the gut microbiota in health and MS. The gut microbiota can affect the body's nervous system function in numerous ways, including the neural regulating pathway, the endocrine pathway-HPA axis, and the immunoregulating pathway (via lymphocyte, cytokines, chemokines, and antigens presenting effect of SCFAs). The normal microbiome has many functions: (1) maintenance of the motility and permeability of the gut; (2) synthesis and secretion of essential vitamins, such as vitamin B12, folate, vitamin K, nicotinic acid, biotin, riboflavin, pyridoxine, panthotenic acid, and thiamine; (3) maintenance of intestinal epithelial functions, such as absorption and secretion; and (4) local stimulation of the development of innate and adaptive immune systems via GALT secreting immune cells, cytokines, and IgAs. When the gut microbiota is in dysbiosis, several diseases may develop, such as MS. The pathology of MS includes increased BBB permeability, destruction of the myelin layer in the CNS, and inflammatory cell infiltration of perivascular tissues. The immunological changes of MS in the periphery are characterized by an increase in pro-inflammatory effector such as CD $4^{+} \mathrm{T}$ cells, monocytes, macrophages, inflammatory dendritic cells, and B cells and a decrease in $\mathrm{CD}^{+}$T cells and CD $4^{+} \mathrm{CD} 25^{+}$FoxP3 ${ }^{+}$Treg cells [84, 87-90]. Patients with MS can exhibit gut microbial dysbiosis, with increases in Methanobrevibacter Akkermansia [128], Desulfovibrionaceae [132], Actinobacteria, Bifidobacterium, Streptococcus [137], Firmicutes, Euryarchaeota [133], Ruminococcus [138], Pseudomonas, Mycoplana, Haemophilus, Blautia, and Dorea [140] and decreases in Butyricimonas [128], Lachnospiraceae, Ruminococcaceae [132], Faecalibacterium, Prevotella, Anaerostipes, Clostridia XIVa and IV Clusters [137], Fusobacteria [133], Bacteroidaceae [138], C. perfringens type A [139], Parabacteroides, and Adlercreutzia [140]. BBB: blood-brain barrier; CNS: central nervous system; HPA axis: hypothalamic-pituitary-adrenal axis; SCFA: short chain fatty acids; APC: antigen presenting cell; GLAT: gut-associated lymphoid tissue; FoxP3: forkhead box 3; Treg: regulatory T cells.

and immunity, and can modulate brain signals, triggering bidirectional signaling via the microbiome-gut-brain axis through the endocrine, immune, nervous, and metabolic systems $[53,54]$. This axis includes a variety of molecular pathways interacting with each other (Figure 1).

2.3.1. Neural Regulation Pathway. The gut microbiota can secrete and regulate neurotransmitters of the central and peripheral nervous systems; intestinal lymphocytes can be stimulated by local environmental changes in the lumen (including changes in the gut microbiota) and release cytokines to activate the endocrine or paracrine systems and consequently affect the CNS. At the same time, the CNS can directly impact the gut via sympathetic nervous system or parasympathetic nervous system, especially of the vagus nerve; the regulations are mainly mediated by the secretion of catecholamines or acetylcholine, which influence ENS circuits $[55,56]$. Gut microbes also produce a range of important components that are implicated in neuroactive and immune regulation, including secreting $\gamma$-aminobutyric acid (GABA), histamine, serotonin, dopamine, and others [57, 58]. 
2.3.2. Endocrine Regulation Pathway. The hypothalamicpituitary-adrenal (HPA) axis comprises the hypothalamus and the pituitary and adrenal glands. When confronted with stress or other stimulants, the HPA axis finally releases glucocorticoids, mineralocorticoids, or catecholamines; all of them can alter gut microbiota composition and increase gut epithelium permeability and immune responses [59-61]. Increased corticosterone levels in stressed mice lead to intestinal dysbiosis that is characterized by the Clostridium genus increase and the Bacteroides genus decrease [62]. Because glucocorticoids have both proinflammatory and anti-inflammatory effects on the peripheral and CNS immune cells, and inflammatory and autoimmune diseases are often associated with impaired HPA axis functionality, such as in RA, IBD, and MS [61, 63, 64].

2.3.3. Immunoregulation Pathway. Gut microbes can modulate the immune response in a variety of ways, such as affecting antigen presenting effect and regulating the production of cytokines and the function of lymphocytes. The gut microbiota plays an important role in the fermentation of indigestible carbohydrates into the three most abundant SCFAs: acetate, propionate, and butyrate. In the human gut, acetate is produced by gut anaerobes, propionate is significantly produced by Bacteroidetes, and butyrate production is mainly by Firmicutes [65-67]. These molecules activate the brain's immune response, which can trigger inflammation in the nervous system and cause a series of neurological symptoms. Butyrate has anti-inflammatory and anticancer functions, and it constitutes an important energy source for colonocytes and has an effect in inhibiting histone deacetylase (epigenetics) [68], generating intestinal and circulating regulatory $\mathrm{T}$ (Treg) cells [69], maintaining blood-brain barrier (BBB) integrity [70], and modulating CNS-microglia activity [71]. SCFAs have also been known to have strong anti-inflammatory effects. They can influence the production of cytokines and have relationship with the G-proteincoupled receptor 43 (GPR43) to elicit an anti-inflammatory effect [72]. The GI microbiome can regulate the development of the host innate and adaptive immune systems via the gutCNS-axis. The microbes are necessary for host immunity generation because in the GI tract, they can format GALTs. The GALT represents the largest immune holder in the human body, containing nearly $80 \%$ of the immune compartments. The regulatory $\mathrm{T}$ cells and autoimmune pathogenic T cells may maturate in the GALT and suppress autoimmune response outside the gut $[15,73]$. Studies with germ-free (GF) mice have shown a thinner mucus layer and Peyer's patches and decrease numbers of secreting IgA plasma cells, $\mathrm{CD}^{+} \mathrm{T}$ cells, and antimicrobial peptides [74-76]. In GF mice, the lymph nodes and spleens are abnormally developed, with decreased numbers of $\mathrm{B}$ and $\mathrm{T}$ cells in the germinal centers and parafollicular region [77].

2.3.4. Metabolic System Regulation Pathway. Gut microbes modulate brain function by the release of metabolites such as immune antigens (peptidoglycan, lipopolysaccharide (LPS), and polysaccharide A (PSA)) with immunological effects $[78,79]$. Normal bacteria can stimulate the production of cross-reactive antibodies (mainly IgA). These antibodies are secreted into the intestine and can play an important role in preventing bacterial infection. PSA derived from Bacteroides fragilis is known as an immunomodulator with inhibitory function in $\mathrm{CD}_{3} 9^{+} \mathrm{FoxP}^{+} \mathrm{T}$ cells and Treg cells [80]. Lipid 654, produced by Bacteroidetes in the human gut, can be a ligand for mouse TLR2 and human and exist in the systemic circulation of healthy humans [81] (Figure 1).

\section{MS/EAE and Gut Microbes}

3.1. MS and EAE. MS is an autoimmune disease in the CNS, which is the main cause of disability in young people in Western countries [82, 83]. Pathological changes associated with MS include the loss of BBB integrity, inflammatory cell infiltration of perivascular tissues, destruction the myelin layer, and axonal damage [84]. The clinical features may be diverse and include limb weakness, paresthesia, fatigue, blurred vision, and cognitive deficits, among others [85]. EAE is the most widely used animal model of MS and resembles its pathological, clinical, and immunological features [86]. The immunological changes in MS/EAE are characterized by increasing proinflammatory cell infiltration, followed by $\mathrm{CD}^{+} \mathrm{T}$ cells with the Th1 or Th17 phenotypes, monocytes, macrophages, inflammatory dendritic cells, and $\mathrm{B}$ cells, and decreasing in $\mathrm{CD}^{+} \mathrm{T}$ cells, $\mathrm{CD} 4^{+} \mathrm{CD} 25^{+}$Forkhead box 3 $\left(\right.$ FoxP $\left.^{+}\right)$Treg cells, and impaired Treg function [84, 87-90].

The etiology of MS remains relatively unknown, and it may include both genetic and environmental factors. Genetic factors: MS often occurs in young women, and the ratio of female to male in MS has increased to an incidence of $3: 1$ over the past decades, indicating a potential role of hormones in the occurrence of MS. Androgens have the ability to reduce the natural killer (NK) cells, toll-like receptor 4, and tumor necrosis factor-alpha (TNF- $\alpha$ ), while they upregulate antiinflammatory molecule production, such as interleukin-10 (IL-10). In contrast, estrogens may enhance the production of the proinflammatory cytokines like IL-1, IL- 6 , and TNF- $\alpha$ $[34,91]$. Over 100 genetic risk factors have been identified for MS, including HLA alleles (HLA-DRB1*1501, DR4, and DR3), transcription factors, adhesion molecules, chemokines, cytokines, and micro-RNA genes [92]. However, the MS is not fully controlled by genetics, as monozygotic twins, sharing $100 \%$ of genetic material, show an approximately $25-30 \%$ lifetime risk for MS when one of them has been diagnosed, suggesting that the genetic background could be interacting with other risk factors [93, 94]. Environmental factors: Previously, it was reported that living at higher latitudes would pose a higher disease risk because of more limited sun exposure leading to possible vitamin D deficiency [95]. Other environment factors include smoking, antibiotic exposure, vaccination, obesity, ethanol abuse, EB virus infection, exposure to air pollutants including PMs (particulate matters), heavy metals, and airborne biological pollutants such as lipopolysaccharide (LPS) and gut microbiota changes [96-101]. Recently, it was found that many of the risk factors listed, including reduced vitamin D intake, smoking, hypercaloric Western diet, vaccination, stress, and alcohol addiction, 
may be related to the gut microbiome dysbiosis [102]. A reduced vitamin $\mathrm{D}$ intake can alter the immune responses, producing FoxP3 ${ }^{+}$Treg cells and reducing $\mathrm{T}$ cells in the gut, which could affect gut microbial populations directly [103]. Smoking can influence the gut microbiome in humans; after smoking cessation, microbial diversity increases and the overall composition of the microbiome changes [104]. Therefore, the dysbiosis of gut microbiota may be involved in the pathogenesis of MS.

3.2. The Microbiome in EAE. The impact of the gut microbiota on the development of MS has been rooted in several preclinical studies in EAE. The gut microbiota plays an essential role in the occurrence and development of the immune system in EAE; it can regulate BBB permeability, limit astrocyte pathogenicity, activate microglia, and express myelin genes [70, 71, 105, 106] (Table 1).

Germ-free (GF) mice show significant defects in both systemic lymphoid and gut-associated tissues, and Peyer's patches are hypoplastic in such animals with greatly decreased number of plasma cells, which produce resident $\mathrm{CD}^{+} \mathrm{T}$ cells and IgA [107]. Although EAE can be induced in GF mice, the severity of EAE was obviously reduced $[108,109]$, due to the inability to form more pathogenic $\mathrm{T}$ cells such as Th17 cells. However, when these mice are colonized with segmented filamentous bacteria, they show a recirculate inflammation in EAE and enhanced disease severity, which increases Th17 cells in the CNS [108]. The gut microbiota may be necessary in the normal $\mathrm{BBB}$ development, since germ-free mice have disrupted $\mathrm{BBB}$ tight junction and increased BBB permeability compared to controls [70].

Because the gut microbiota has immune regulation functions, attempts have been made to treat EAE by inducing changes in the gut microbiota. Ochoa reported that treatment with oral antibiotics in EAE can reduce intestinal symbiotic gut and delay the development of EAE, while the intraperitoneal injection of antibiotics in mice had no obvious impact on the development of EAE, which suggests that gut microbiota changes are associated with the development of EAE [42]. The protective effect of antibiotic treatment in EAE is related with a regulation of the abnormal in $\mathrm{T}$ cell responses in the CNS and the GI tract, diminishing proinflammatory cells, like Th1 and Th17 cells and their cytokines IFN and IL-17A and enhancing anti-inflammatory response, including increasing secretion of FoxP3 ${ }^{+}$Treg cells, IL-10 and IL-13 [108-112]. Except for changes in T-cell subsets, $\mathrm{B}$ cells can recruit and dendritic cells can activate Th1 and Th17 cells in EAE $[108,109]$. Some studies have suggested that some bacterial strains have beneficial effects on EAE by protecting mice from disease exacerbation [113-116]. One of the common bacteria $B$. fragilis has the ability to produce polysaccharide A (PSA), which can induce naive T-cell differentiation to produce IL-10 FoxP3 ${ }^{+}$CD4 Treg cells and protect mice from CNS demyelinating diseases $[114,117]$. The oral administration of PSA could have both preventive effect and therapeutic effect to protect against EAE [102]. Other bacteria such as the Bifidobacterium may also decrease EAE symptoms [113]. The oral administration of Lactobacillus spp. and other lactic acid-producing bacteria have been demonstrated to reduce the clinical score of EAE [111, 118, 119]. Mangalam recently showed that Prevotella histicola can suppress disease in EAE, as it induced $\mathrm{CD} 4{ }^{+} \mathrm{FoxP}^{+}$regulatory $\mathrm{T}$ cells and tolerogenic dendritic cells and suppressed macrophages [13, 120]. CD44 deficiency alters three phyla (Bacteroidetes, Firmicutes, and Proteobacteria) of gut microbes, which in turn may play a crucial role in suppressing inflammatory T-cell differentiation accounting for the amelioration of EAE [121]. Autoreactive $\mathrm{CD}^{+}$-induced intraepithelial lymphocytes, which are influenced by stimuli from the gut environment, can also suppress activity against $\mathrm{T}$ cell-mediated EAE [73]. The oral administration of Salmonella typhimurium could increase Treg frequency and decrease Th1 and Th17 cells, which would lead to a decrease in EAE clinical score $[115,122,123]$. Additionally, recent studies have indicated that Bacteroides fragilis and Clostridia clusters XIVa and IV, which derived from human feces, may have the ability to induce Foxp $3^{+}$Treg and be able to suppress inflammatory response in EAE $[114,124,125]$.

3.3. Gut Microbiota in MS. As mentioned above, the gut bacteria have a symbiotic relationship with the host, which could help the host maintain a healthy stable state. At the phylum level, the fecal microbiota is mainly constituted of Bacteroidetes and Firmicutes and with smaller amounts of Verrucomicrobia, Euryarchaeota, and Proteobacteria. In the last few years, several studies have demonstrated that patients with MS exhibit gut microbial dysbiosis with both enrichment and depletion of certain bacterial populations compared to healthy controls (Table 2). Recently, the studies reported that fecal content isolated from the patients with MS transferred to mice increased EAE incidence or severity, which provide the evidence that MS-derived microbiota contain factors that regulate adaptive autoimmune responses and precipitate an MS-like autoimmune disease in a transgenic mouse model, suggesting the potential functional effects associated with altered microbiotas observed in MS and targeting microbiota as a therapeutic strategy in MS [126, 127].

Jangi et al. showed increases in Methanobrevibacter (Euryarchaeota phylum) and in Akkermansia (Verrucomicrobia phylum) and decreases in Butyricimonas in MS, which correlates with the gene expression of interferon signaling, dendritic cell maturation, and NF-kB signaling pathways in circulating monocytes and $\mathrm{T}$ cells [128]. In treated patients with MS with interferon- $\beta$ (IFN- $\beta$ ) and glatiramer acetate (GA), there was an increased number of Sutterella and Prevotella and a decreased number of Sarcina compared to those in untreated patients [128]. Akkermansia have immunoregulatory effects on changing mucin into SCFA, and they could also play a reverse role in degrading the mucus layer in proinflammation function $[129,130]$. The Butyricimonas species are butyrate-producing bacteria and have antiinflammatory action by inducing Treg cells in the gut, and a decrease in Butyricimonas will decrease SCFA production [131]. Tremlett conducted three experiments in pediatric MS and found that Firmicutes, Archaea Euryarchaeota, and Proteobacteria (Desulfovibrionaceae) increase in patients with 


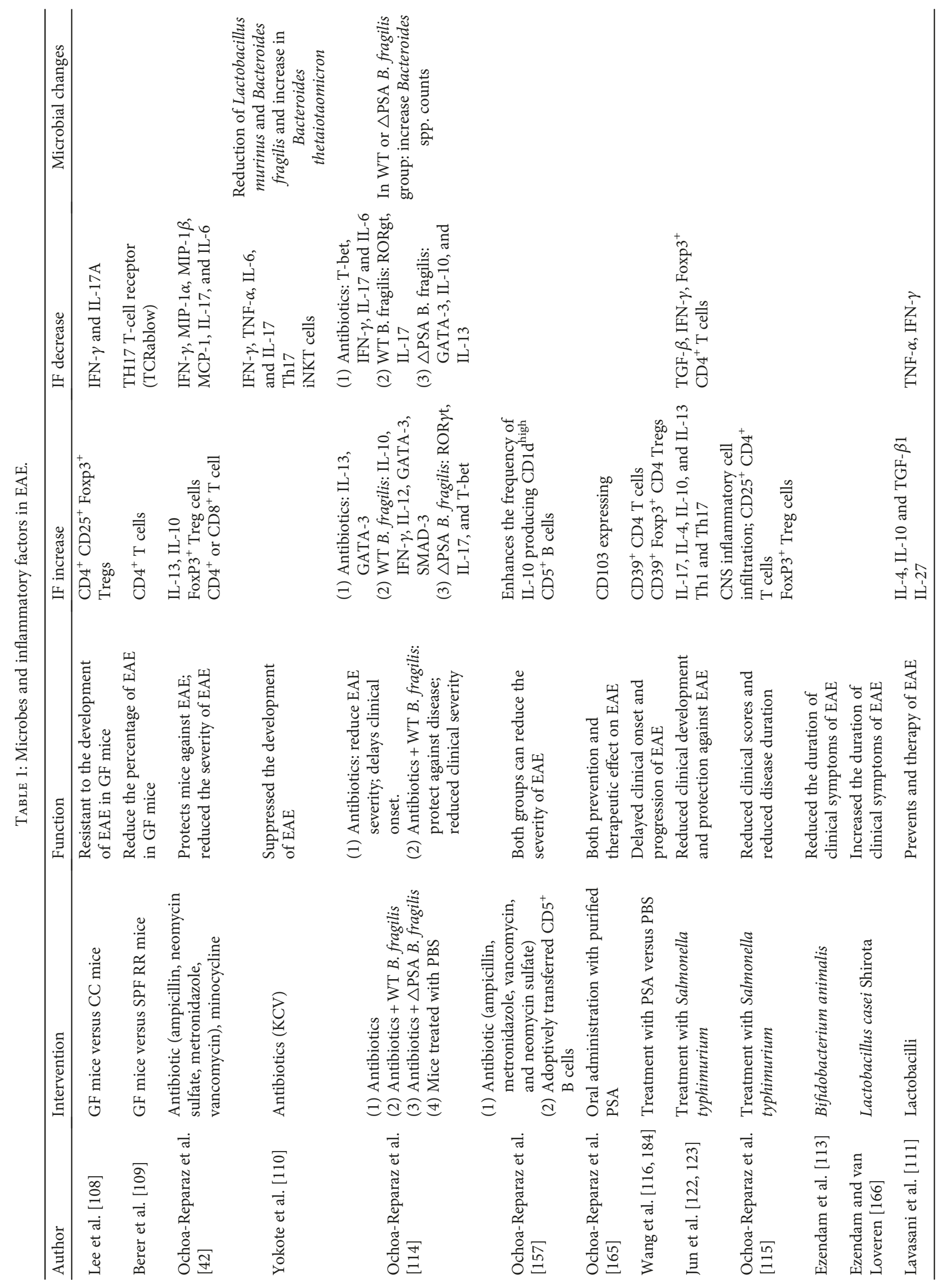




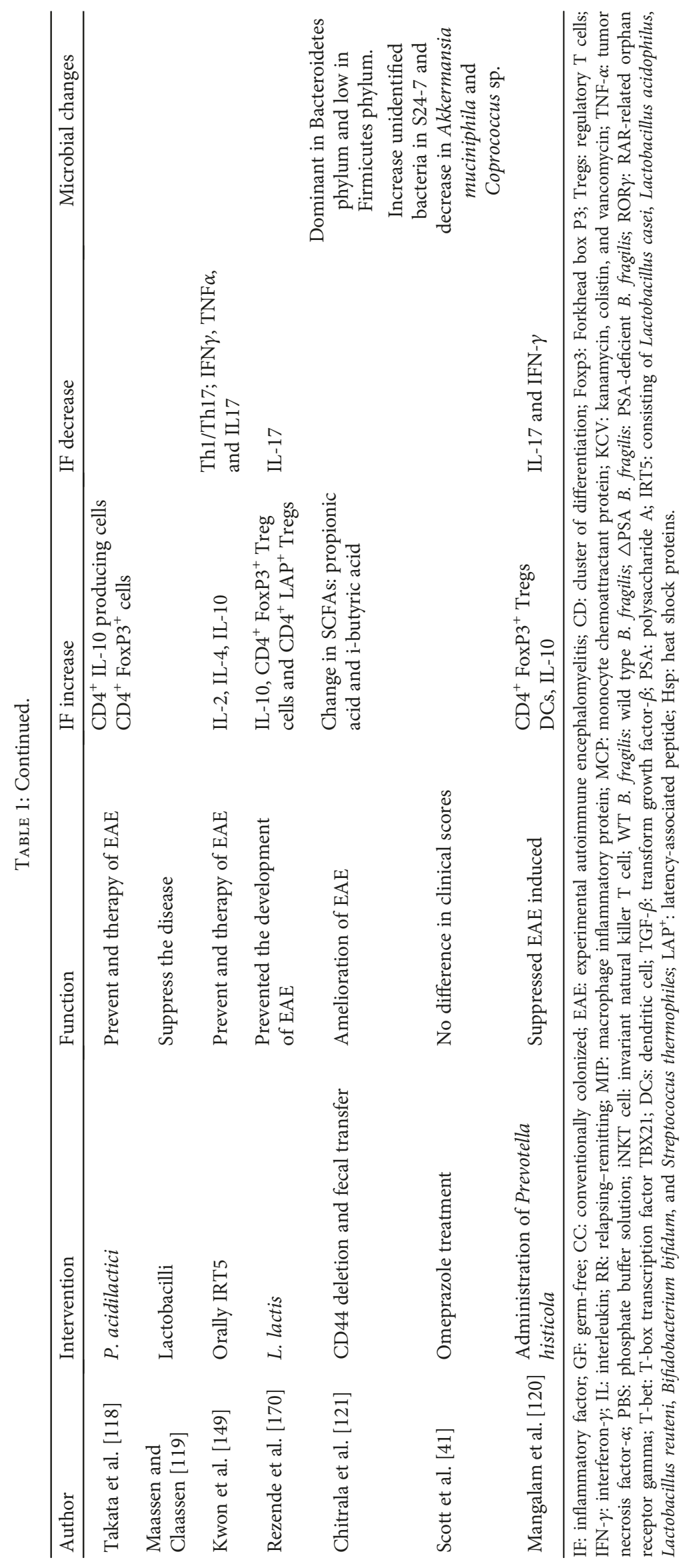




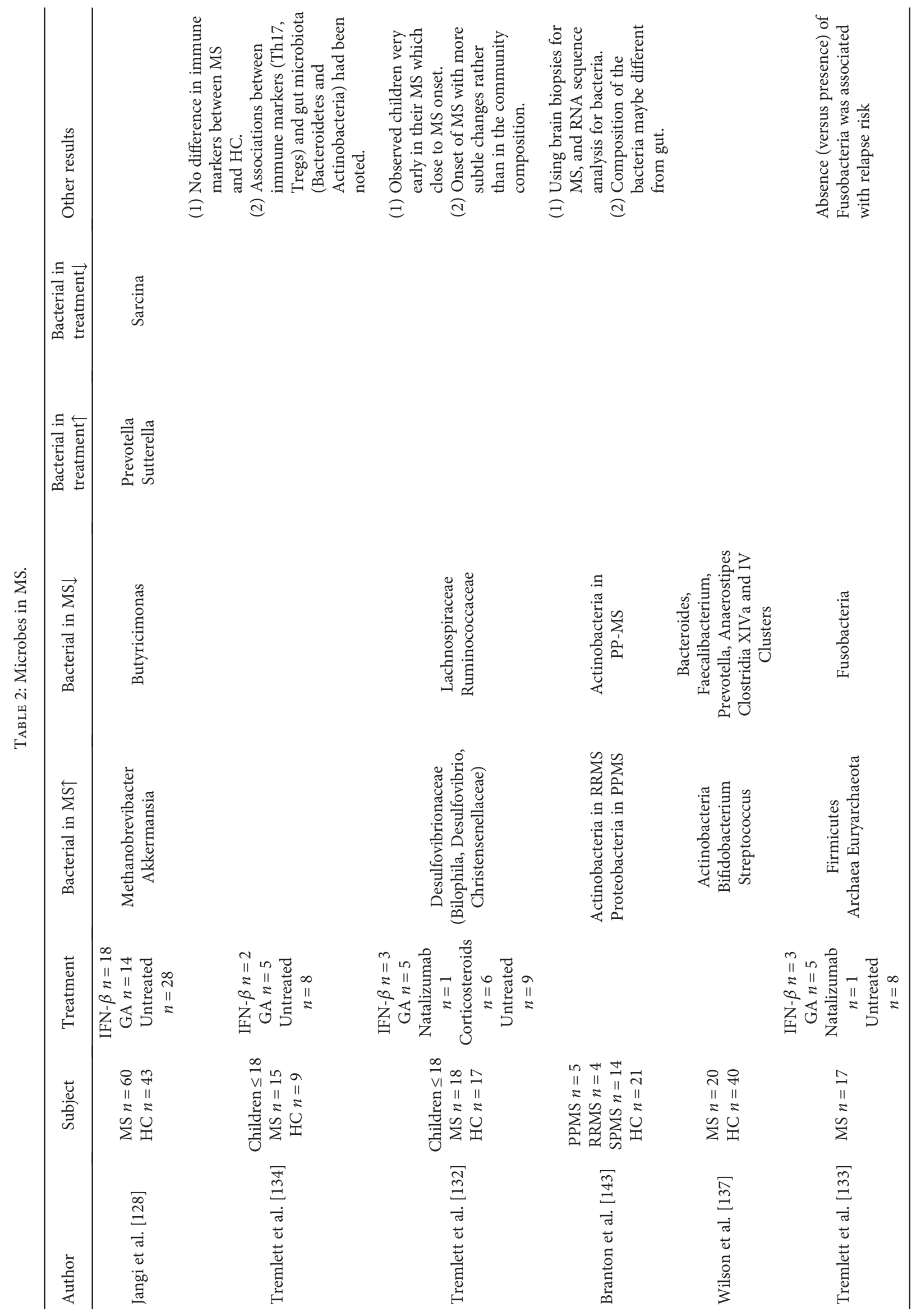




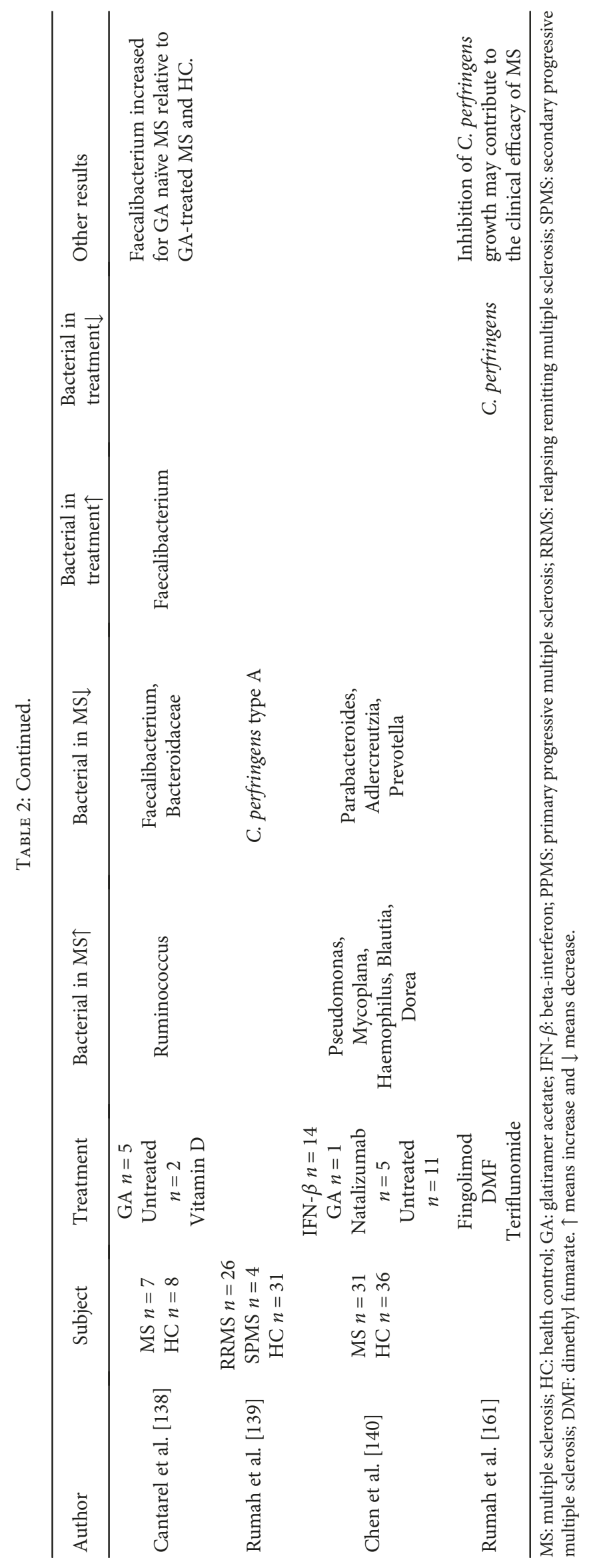


MS, while Lachnospira (Lachnospiraceae), Verrucomicrobia (Ruminococcaceae), and Fusobacteria decrease, and MS in children with the absence (versus presence) of Fusobacteria was associated with relapse risk [132-134]. Tremlett found no difference in immune markers between MS and controls; however, she discovered that Bacteroidetes were inversely associated with Th17 only in MS and Fusobacteria correlated with Tregs only in controls [134]. A study with 20 patients with MS and 40 healthy controls in Japan demonstrated that altered intestinal microbiota in patients with relapsing remitting MS (RRMS) involved increased Actinobacteria, Bifidobacterium, and Streptococcus and decreased Bacteroides, Faecalibacterium, Prevotella, Anaerostipes, and Clostridia XIVa and IV clusters. Clostridium clusters XIVa and IV constitute a $10-40 \%$ of the bacteria in the healthy gut [135-137]. The MS patients with expanded disability status score $($ EDSS $) \leq 3.0$ who received GA treatment were shown to have larger numbers of Bacteroidaceae, Ruminococcus, Lactobacillaceae, and Clostridium compared to the numbers seen in untreated patients [138]. After vitamin D supplementation, Faecalibacterium increases in GA naive MS relative to GA-treated MS and healthy controls [138]. Rumah et al. isolated epsilon toxin- (ETX-) producing Clostridium perfringens type B from a young woman with MS and found that $10 \%$ of their patients with MS had ETX-specific antibodies compared to only $1 \%$ of controls. ETX can disrupt the BBB and bind with myelin, which may be a potential trigger of MS [139]. In contrast, Clostridium perfringens type $\mathrm{A}$ which is commensal with humans was nearly $50 \%$ in healthy controls and only $23 \%$ in MS patients [139]. Chen et al. also reported dysbiosis in 31 patients and 36 controls in a study with patients with RRMS and increased abundance of Pseudomonas, Mycoplana, Haemophilus, Blautia, and Dorea genera and depleted Parabacteroides, Adlercreutzia, and Prevotella in patients with MS [140]. Dorea have been considered to be part of the healthy gut microbiota, but its higher abundance in patients with MS and IBD has suggested a proinflammatory role for this bacterium, and Schirmer et al. showed that Doreacerat in species can induce IFN- $\gamma$, metabolize sialic acids, and degrade mucin for its proinflammatory functions $[13,141,142]$. Apart from the gut, one study also reported the presence of bacteria in brain biopsies. Biopsy samples of brain white matter showed a higher abundance of Actinobacteria in RRMS and Proteobacteria in primary progressive MS (PPMS) and a decrease of Actinobacteria in PPMS [143]. Recently, Farrokhi et al. demonstrated unique lipopeptide bacteria that originate from serine lipopeptide, lipid 654, which is produced by some Bacteroidetes commensal species, providing further evidence for an association between the bacteria and MS. Kleinewietfeld et al. demonstrated that lipid 654 is expressing at lower levels in the MS patients' serum than in healthy controls'. So lipid 654 may be a useful biomarker to evaluate MS activity [144, 145].

Overall, patients with MS usually have gut dysbiosis and often reduced numbers of Faecalibacterium, Bacteroidaceae, and Prevotella. After drug therapy, the gut microbiota of patients with MS changes; thus, regulating gut bacteria could a future direction for treatment in MS.

\section{Treatments in MS}

Currently, the primary goal of therapy in MS is symptom improvement after a disease attack, preventing new attacks and decreasing the rate of neurodegeneration in the CNS. Existing therapies available for patients mainly rely on nonspecific treatments, such as corticosteroids, immunosuppressants, and immunomodulating drugs, which often result in drug resistance or severe side effects [146]. As mentioned above, the gut microbiota plays an important role in the development of MS. Alterations in the gut microbiota in MS/EAE can also influence the clinical symptoms and inflammatory factors, which could help us find a new strategy or target to treat MS.

4.1. Dietary Modification. As mentioned earlier, dietary habits can affect intestinal microbe composition. There is an obvious difference in the gut microbiota composition between obese and normal-weight individuals, and obese individuals have reduced diversity in their microbiome especially at a lower level of Bacteroidetes [30]. Studies on the effect of Westernized diet with high fat on mice have shown changes in the gut flora, with an increasing in proinflammatory plasma free fatty acids and increased severity in EAE $[147,148]$. The gut microbiota in the mice can be changed easily within only one day when their diet switches from a plant polysaccharide-rich, low-fat diet to a high-sugar/highfat Western diet, which also changes microbiome metabolic pathways and alters the gene expression of the microbiome [102]. A restricted calorie diet can improve the EAE symptoms, whereas a high-salt diet causes disease exacerbation in EAE by promoting the expansion of macrophages and proinflammatory $\mathrm{T}$ cells, and Th17 differentiation, and also causing restraint in remyelination [113, 118, 149-152]. Middle- and long-chain fatty acids from dietary intake or microbial production promote pathogenic T-cell differentiation in the gut and then induce CNS inflammation. Conversely, SCFA can lead to disease amelioration by protective regulatory $\mathrm{T}$-cell expansion [153]. A study also showed a similar trends on MS in human, suggesting that high sodium intake would worsen the disease [154]. Vitamin D levels are changed in the gut microbiome in MS, which can promote the differentiation of Treg, and the level of Vitamin D is important in maintaining microbiome system balance $[103,155,156]$. Studies have recently showed a direct connection between dietary tryptophan and the symptoms of EAE; deficiency of the antihyaluronidase reaction in astrocytes or lack of dietary tryptophan will fail to recover during the chronic stage of EAE [92].

4.2. Drugs. Antibiotic drugs can easily affect the components of the microbiome. Numerous studies have found that oral antibiotics can reduce in intestinal symbiotic gut and delay the development of EAE [42, 110, 114, 157, 158]. Broadspectrum antibiotics can alter the population of $\mathrm{T}$ cells in the GALT and in peripheral lymphoid tissues to reduce the susceptibility to EAE, and the total number of Foxp $3^{+}$Tregs was significantly increased with a corresponding increase in IL-10 production [159]. A study that administered ciprofloxacin in healthy volunteers over a 10 -month period found that 
the fecal microbiota reached a stable state similar, yet distinct, from the pretreatment state [160]. Minocycline is a kind of tetracycline antibiotic that often used for treating acne, which was also used to reduce disease severity in EAE both prophylactically and therapeutically [137]. Antibiotic therapy may be beneficial in the treatment of MS.

Other drugs, such as fingolimod, teriflunomide, and dimethyl fumarate, have immunomodulatory functions and have been shown to inhibit $C$. perfringens growth; therefore, the inhibition of $C$. perfringens may contribute to the clinical efficacy of these disease-modifying drugs [161].

4.3. Probiotics Treatment. Studies have suggested that probiotics can influence systemic immune responses, and the mechanisms behind the efficacy of probiotics may include maintaining the function of the gastrointestinal-epithelial barrier, increasing antimicrobial peptide production, and helping the activation of the host immune system in response to pathogens. Thus, probiotics could be used as adjuvant therapy to treat immune-mediated diseases $[162,163]$.

In recent years, an increasing number of animal experiments have provided evidence that the administration of probiotics can improve CNS symptoms. Long bifidobacterium (b. Longum), Breve bifidobacterium, Bifidobacterium infantis, Lactobacillus helveticus, Rhamnose lactobacillus, plant Lactobacillus, and Lactobacillus casei have been shown to effectively improve behavior, such as anxiety and depression, in animal models [164].

Infection with Lactobacillus casei Shirota or oral Lactobacillus farciminis, Bifidobacterium bifidum, Bacteroides fragilis, and Bifidobacterium animalis in mice resulted in Treg cell induction by promoting the secretion of IL-10, which was followed by IFN- $\gamma$, TNF- $\alpha$, and IL-17 reduction and inflammatory Th1/Th17 decrease, and were shown to be EAE resistant or reduced the symptoms of MS [111, 113, 114, 118, 149, 165, 166].

Takata et al. found that Candida kefyr (C. kefyr) could alleviate the severity EAE symptoms. The bacteria can reduce the quantity of intestinal lamina propria Thl7 cells and cause IL- 6 decline; at the same time, Tregs in the mesenteric lymph nodes and $\mathrm{CDlO3}^{+}$regulatory dendritic cells increase. The analysis of 16s-rRNA in rats showed the increased incidence of Lactobacillus in the feces and decrease in polymorphic Bacillus [167].

The periodontal Porphyromonas gingivalis may enhance glial cell activation and proinflammatory responses and exacerbate EAE $[168,169]$. In contrast, Candida kefyr found that fermented foods can reduce the EAE [167].

Recently, studies have shown that using heat-killed bacteria like probiotic Pediococcu sacidilactici strain R037, PSA purified from B. fragilis [165], and heat shock protein 65 (Hsp65) produced from the Lactococcus lactis [170] also reduced the severity of EAE $[114,115,118,167,170]$. These findings suggest that bacteria-derived products may have therapeutic potential in MS and EAE.

4.4. Fecal Microbial Transplantation (FMT). Currently, FMT has been paid wide attention for restoring intestinal microecological balance, which may be significantly efficacious and have less adverse reactions. Now FMT's adaptive diseases has been extended from the initial intestinal disorders to the metabolism, neurosis, autoimmunity, allergic diseases, and cancer prevention [171-173]. The results of clinical trials have shown that FMT can improve the walking ability in MS and alleviate autistic behavior as well as improve the neurological symptoms of PD $[171,174]$. Borody et al. reported three patients with MS with severe constipation treated with FMT, which reduced the neurological symptoms and normalized walking. Unfortunately, the study had a small sample and was uncontrolled [175]. So far, FMT has been limited to individual cases, and clinical applications require more rigorous scientific evidence and human experimental verification in large samples.

4.5. Others. Parasites, in particular helminths or worms, have an effect on Th2 cell induction to produce anti-inflammatory cytokines, including IL-4, IL-10, IL-13, and TGF-b [176]. Helminths have provided therapeutic effects in patients suffering from MS and ulcerative colitis [176]. In addition, patients with MS naturally infected with helminths had fewer relapses than uninfected patients, and elimination of the parasites worsened their condition [177, 178]. Based on these findings, helminths may be a new method of MS treatment.

As described above, the alterations in the microbial composition of the gut may drive disease, which is a process called as dysbiosis. In recent years, more and more evidence suggest that the dysbiosis of the gut microbiome may be the cause of MS and other disorders, such as depression and Parkinson's disease [179-181]. However, the pathogenesis of these disorders is more complex than the dysbiosis of gut microbiome speculated [182], which may be one of the pathogenic factors for driving these disorders. Also it might be an alteration of microbial architecture from healthy condition with immune balance shifting toward an immune imbalance with inflammatory phenotype [183].

\section{Conclusion}

This review focused on exploring the complex roles of the alterations in the gut microbiome in MS and EAE. Dysbiosis in the gut microbiome may be one of the causes of the numerous diseases, including MS. Gut therapies including dietary modification, drug treatment, probiotics, FTX, and perhaps helminth treatment may be used in MS in the future. However, there is still a long way to go, as more rigorous scientific evidence with larger sample sizes are required for clinical application.

\section{Conflicts of Interest}

The authors have no competing interests to declare.

\section{Acknowledgments}

This study was supported by grants from The First Hospital, Jilin University, Changchun, International Science and Technology Cooperation Program of Jilin Provincial Science and Technology Development of China (no. 20150414011GH); 
Norman Bethune Cultivation Plan of Jilin University (no. 2015320); the National Natural Science Foundation (nos. 81471216, 81671186, 81671177, and 31600820); and the Swedish Research Council (2015-03005).

\section{References}

[1] A. Perez-Lopez, J. Behnsen, S. P. Nuccio, and M. Raffatellu, "Mucosal immunity to pathogenic intestinal bacteria," Nature Reviews Immunology, vol. 16, no. 3, pp. 135-148, 2016.

[2] C. Reinoso Webb, I. Koboziev, K. L. Furr, and M. B. Grisham, "Protective and pro-inflammatory roles of intestinal bacteria," Pathophysiology, vol. 23, no. 2, pp. 67-80, 2016.

[3] E. C. Rosser and C. Mauri, "A clinical update on the significance of the gut microbiota in systemic autoimmunity," Journal of Autoimmunity, vol. 74, pp. 85-93, 2016.

[4] S. Fraune and T. C. Bosch, "Why bacteria matter in animal development and evolution," BioEssays, vol. 32, no. 7, pp. 571-580, 2010.

[5] R. E. Ley, P. J. Turnbaugh, S. Klein, and J. I. Gordon, "Microbial ecology: human gut microbes associated with obesity," Nature, vol. 444, no. 7122, pp. 1022-1023, 2006.

[6] A. L. Kau, P. P. Ahern, N. W. Griffin, A. L. Goodman, and J. I. Gordon, "Human nutrition, the gut microbiome and the immune system," Nature, vol. 474, no. 7351, pp. 327336, 2011.

[7] S. P. Adrian Budhram, M. Kremenchutzky, and M. Silverman, "Breaking down the gut microbiome composition in multiple sclerosis," Multiple Sclerosis Journal, vol. 23, no. 5, pp. 628636, 2017.

[8] X. Zhang, D. Y. Zhang, H. J. Jia et al., "The oral and gut microbiomes are perturbed in rheumatoid arthritis and partly normalized after treatment," Nature Medicine, vol. 21, no. 8, pp. 895-905, 2015.

[9] A. Parashar and M. Udayabanu, "Gut microbiota: implications in Parkinson's disease," Parkinsonism \& Related Disorders, vol. 38, pp. 1-7, 2017.

[10] S. Westfall, N. Lomis, I. Kahouli, S. Y. Dia, S. P. Singh, and S. Prakash, "Microbiome, probiotics and neurodegenerative diseases: deciphering the gut brain axis," Cellular and Molecular Life Sciences, vol. 74, no. 20, pp. 37693787, 2017.

[11] L. Galland, "The gut microbiome and the brain," Journal of Medicinal Food, vol. 17, no. 12, pp. 1261-1272, 2014.

[12] A. Swidsinski, V. Loening-Baucke, H. Lochs, and L. P. Hale, "Spatial organization of bacterial flora in normal and inflamed intestine: a fluorescence in situ hybridization study in mice," World Journal of Gastroenterology, vol. 11, no. 8, pp. 1131-1140, 2005.

[13] S. Shahi, S. Freedman, and A. Mangalam, "Gut microbiome in multiple sclerosis: the players involved and the roles they play," Gut Microbes, vol. 8, no. 6, pp. 607-615, 2017.

[14] A. Picca, F. Fanelli, R. Calvani et al., "Gut dysbiosis and muscle aging: searching for novel targets against sarcopenia," Mediators of Inflammation, vol. 2018, Article ID 7026198, 15 pages, 2018.

[15] D. W. Mielcarz and L. H. Kasper, "The gut microbiome in multiple sclerosis," Current Treatment Options in Neurology, vol. 17, no. 4, p. 18, 2015.
[16] J. Li, H. Jia, X. Cai et al., "An integrated catalog of reference genes in the human gut microbiome," Nature Biotechnology, vol. 32, no. 8, pp. 834-841, 2014.

[17] P. Hugon, J. C. Dufour, P. Colson, P. E. Fournier, K. Sallah, and D. Raoult, "A comprehensive repertoire of prokaryotic species identified in human beings," The Lancet Infectious Diseases, vol. 15, no. 10, pp. 1211-1219, 2015.

[18] E. M. Mowry and J. D. Glenn, "The dynamics of the gut microbiome in multiple sclerosis in relation to disease," Neurologic Clinics, vol. 36, no. 1, pp. 185-196, 2018.

[19] H. E. Blum, "The human microbiome," Advances in Medical Sciences, vol. 62, no. 2, pp. 414-420, 2017.

[20] J. Penders, C. Thijs, C. Vink et al., "Factors influencing the composition of the intestinal microbiota in early infancy," Pediatrics, vol. 118, no. 2, pp. 511-521, 2006.

[21] S. Ghaisas, J. Maher, and A. Kanthasamy, "Gut microbiome in health and disease: linking the microbiome-gut-brain axis and environmental factors in the pathogenesis of systemic and neurodegenerative diseases," Pharmacology \& Therapeutics, vol. 158, pp. 52-62, 2016.

[22] F. Backhed, J. Roswall, Y. Peng et al., "Dynamics and stabilization of the human gut microbiome during the first year of life," Cell Host \& Microbe, vol. 17, no. 5, pp. 690-703, 2015.

[23] T. Yatsunenko, F. E. Rey, M. J. Manary et al., "Human gut microbiome viewed across age and geography," Nature, vol. 486, pp. 222-227, 2012.

[24] M. G. Dominguez-Bello, E. K. Costello, M. Contreras et al., "Delivery mode shapes the acquisition and structure of the initial microbiota across multiple body habitats in newborns," Proceedings of the National Academy of Sciences of the United States of America, vol. 107, no. 26, pp. 1197111975, 2010.

[25] P. Bager, J. Wohlfahrt, and T. Westergaard, "Caesarean delivery and risk of atopy and allergic disesase: meta-analyses," Clinical \& Experimental Allergy, vol. 38, no. 4, pp. 634-642, 2008.

[26] J. E. Koenig, A. Spor, N. Scalfone et al., "Succession of microbial consortia in the developing infant gut microbiome," Proceedings of the National Academy of Sciences of the United States of America, vol. 108, Supplement 1, pp. 4578-4585, 2011.

[27] J. M. Rodriguez, K. Murphy, C. Stanton et al., "The composition of the gut microbiota throughout life, with an emphasis on early life," Microbial Ecology in Health and Disease, vol. 26, article 26050, 2015.

[28] M. Simren, G. Barbara, H. J. Flint et al., "Intestinal microbiota in functional bowel disorders: a Rome foundation report," Gut, vol. 62, no. 1, pp. 159-176, 2013.

[29] J. Dicksved, J. Halfvarson, M. Rosenquist et al., "Molecular analysis of the gut microbiota of identical twins with Crohn's disease," The ISME Journal, vol. 2, no. 7, pp. 716-727, 2008.

[30] P. J. Turnbaugh, M. Hamady, T. Yatsunenko et al., "A core gut microbiome in obese and lean twins," Nature, vol. 457, no. 7228, pp. 480-484, 2009.

[31] G. Erwin and A. D. L. A. Zoetendal, "The host genotype affects the bacterial community in the human gastronintestinal tract," Microbial Ecology in Health and Disease, vol. 13, no. 3, pp. 129-134, 2009.

[32] S. Mueller, K. Saunier, C. Hanisch et al., "Differences in fecal microbiota in different European study populations in relation to age, gender, and country: a cross-sectional study," 
Applied and Environmental Microbiology, vol. 72, no. 2, pp. 1027-1033, 2006.

[33] E. Jašarević, K. E. Morrison, and T. L. Bale, "Sex differences in the gut microbiome-brain axis across the lifespan," Philosophical Transactions of the Royal Society B: Biological Sciences, vol. 371, no. 1688, article 20150122, 2016.

[34] A. Gomez, D. Luckey, and V. Taneja, "The gut microbiome in autoimmunity: sex matters," Clinical Immunology, vol. 159, no. 2, pp. 154-162, 2015.

[35] J. G. Markle, D. N. Frank, S. Mortin-Toth et al., "Sex differences in the gut microbiome drive hormone-dependent regulation of autoimmunity," Science, vol. 339, no. 6123, pp. 1084-1088, 2013.

[36] L. Yurkovetskiy, M. Burrows, A. A. Khan et al., "Gender bias in autoimmunity is influenced by microbiota," Immunity, vol. 39, no. 2, pp. 400-412, 2013.

[37] L. A. David, C. F. Maurice, R. N. Carmody et al., "Diet rapidly and reproducibly alters the human gut microbiome," Nature, vol. 505, no. 7484, pp. 559-563, 2014.

[38] J. Zimmer, B. Lange, J. S. Frick et al., "A vegan or vegetarian diet substantially alters the human colonic faecal microbiota," European Journal of Clinical Nutrition, vol. 66, no. 1, pp. 5360, 2012.

[39] S. E. Power, P. W. O'Toole, C. Stanton, R. P. Ross, and G. F. Fitzgerald, "Intestinal microbiota, diet and health," British Journal of Nutrition, vol. 111, no. 03, pp. 387-402, 2014.

[40] C. De Filippo, D. Cavalieri, M. Di Paola et al., "Impact of diet in shaping gut microbiota revealed by a comparative study in children from Europe and rural Africa," Proceedings of the National Academy of Sciences of the United States of America, vol. 107, no. 33, pp. 14691-14696, 2010.

[41] A. Scott, S. T. Sands, T. M. Yankee, B. L. Parker, A. C. Ericsson, and S. M. LeVine, "The effect of omeprazole on the development of experimental autoimmune encephalomyelitis in c57bl/6j and sjl/j mice," BMC Research Notes, vol. 7, no. 1, p. 605, 2014.

[42] J. Ochoa-Reparaz, D. W. Mielcarz, L. E. Ditrio et al., "Role of gut commensal microflora in the development of experimental autoimmune encephalomyelitis," The Journal of Immunology, vol. 183, no. 10, pp. 6041-6050, 2009.

[43] L. Biedermann and G. Rogler, "The intestinal microbiota: its role in health and disease," European Journal of Pediatrics, vol. 174, no. 2, pp. 151-167, 2015.

[44] S. N. M. E. Rezasoltani, M. Norouzinia, and A. H. Asadzadeh, "The necessity of gut microbiome characterization in diseases prevention and therapy," Gastroenterology and Hepatology From Bed to Bench, vol. 10, no. 2, pp. 150-151, 2017.

[45] J. LeBlanc, C. Milani, G. de Giori, F. Sesma, D. van Sinderen, and M. Ventura, "Bacteria as vitamin suppliers to their host: a gut microbiota perspective," Current Opinion in Biotechnology, vol. 24, no. 2, pp. 160-168, 2013.

[46] A. A. Abou-Zeid, Y. M. Shehata, and R. el-Sherbeny, "Microbial production of cobalamin (Vitamin $\left.\mathrm{B}_{12}\right)$," Zentralblatt für Bakteriologie, Parasitenkunde, Infektionskrankheiten und Hygiene. Zweite Naturwissenschaftliche Abteilung: Allgemeine, Landwirtschaftliche und Technische Mikrobiologie, vol. 128, no. 3-4, pp. 285-296, 1973.

[47] A. Pompei, L. Cordisco, A. Amaretti, S. Zanoni, D. Matteuzzi, and M. Rossi, "Folate production by bifidobacteria as a potential probiotic property," Applied and Environmental Microbiology, vol. 73, no. 1, pp. 179-185, 2007.
[48] M. J. Hill, "Intestinal flora and endogenous vitamin synthesis," European Journal of Cancer Prevention, vol. 6, Supplement 1, pp. S43-S45, 1997.

[49] R. Correa-Oliveira, J. L. Fachi, A. Vieira, F. T. Sato, and M. A. Vinolo, "Regulation of immune cell function by short-chain fatty acids," Clinical \& Translational Immunology, vol. 5, no. 4, article e73, 2016.

[50] M. D. Gershon, "The enteric nervous system: a second brain," Hospital Practice, vol. 34, no. 7, pp. 31-52, 1999.

[51] M. B. Hansen, "The enteric nervous system I: organisation and classification," Basic \& Clinical Pharmacology \& Toxicology, vol. 92, no. 3, pp. 105-113, 2003.

[52] R. K. Goyal and I. Hirano, "The enteric nervous system," The New England Journal of Medicine, vol. 334, no. 17, pp. 1106$1115,1996$.

[53] J. M. Yano, K. Yu, G. P. Donaldson et al., "Indigenous bacteria from the gut microbiota regulate host serotonin biosynthesis," Cell, vol. 161, no. 2, pp. 264-276, 2015.

[54] J. D. Crane, R. Palanivel, E. P. Mottillo et al., "Inhibiting peripheral serotonin synthesis reduces obesity and metabolic dysfunction by promoting brown adipose tissue thermogenesis," Nature Medicine, vol. 21, no. 2, pp. 166-172, 2015.

[55] E. A. Mayer, K. Tillisch, and A. Gupta, "Gut/brain axis and the microbiota," The Journal of Clinical Investigation, vol. 125, no. 3, pp. 926-938, 2015.

[56] L. I. Weinstein, A. Revuelta, and R. H. Pando, "Catecholamines and acetylcholine are key regulators of the interaction between microbes and the immune system," Annals of the New York Academy of Sciences, vol. 1351, no. 1, pp. 39-51, 2015.

[57] E. Barrett, R. P. Ross, P. W. O'Toole, G. F. Fitzgerald, and C. Stanton, " $\gamma$-Aminobutyric acid production by culturable bacteria from the human intestine," Journal of Applied Microbiology, vol. 113, no. 2, pp. 411-417, 2012.

[58] M. Lyte, "Microbial endocrinology in the microbiome-gutbrain axis: how bacterial production and utilization of neurochemicals influence behavior," PLoS Pathogens, vol. 9, no. 11, article e1003726, 2013.

[59] A. J. Park, J. Collins, P. A. Blennerhassett et al., "Altered colonic function and microbiota profile in a mouse model of chronic depression," Neurogastroenterology \& Motility, vol. 25, no. 9, pp. 733-e575, 2013.

[60] A. Ait-Belgnaoui, H. Durand, C. Cartier et al., "Prevention of gut leakiness by a probiotic treatment leads to attenuated HPA response to an acute psychological stress in rats," Psychoneuroendocrinology, vol. 37, no. 11, pp. 1885-1895, 2012.

[61] M. A. Bellavance and S. Rivest, "The HPA - immune axis and the immunomodulatory actions of glucocorticoids in the brain," Frontiers in Immunology, vol. 5, p. 136, 2014.

[62] M. T. Bailey, S. E. Dowd, J. D. Galley, A. R. Hufnagle, R. G. Allen, and M. Lyte, "Exposure to a social stressor alters the structure of the intestinal microbiota: implications for stressor-induced immunomodulation," Brain, Behavior, and Immunity, vol. 25, no. 3, pp. 397-407, 2011.

[63] C. Hueston and T. Deak, "The inflamed axis: the interaction between stress, hormones, and the expression of inflammatory-related genes within key structures comprising the hypothalamic-pituitary-adrenal axis," Physiology \& Behavior, vol. 124, pp. 77-91, 2014.

[64] M. N. Silverman and E. M. Sternberg, "Glucocorticoid regulation of inflammation and its functional correlates: from 
HPA axis to glucocorticoid receptor dysfunction," Annals of the New York Academy of Sciences, vol. 1261, no. 1, pp. 5563, 2012.

[65] S. Macfarlane and G. T. Macfarlane, "Regulation of shortchain fatty acid production," Proceedings of the Nutrition Society, vol. 62, no. 01, pp. 67-72, 2003.

[66] P. Louis and H. J. Flint, "Formation of propionate and butyrate by the human colonic microbiota," Environmental Microbiology, vol. 19, no. 1, pp. 29-41, 2017.

[67] N. de Clercq, M. N. Frissen, A. K. Groen, and M. Nieuwdorp, "Gut microbiota and the gut-brain axis: new insights in the pathophysiology of metabolic syndrome," Psychosomatic Medicine, vol. 79, no. 8, pp. 874-879, 2017.

[68] M. Waldecker, T. Kautenburger, H. Daumann, C. Busch, and D. Schrenk, "Inhibition of histone-deacetylase activity by short-chain fatty acids and some polyphenol metabolites formed in the colon," The Journal of Nutritional Biochemistry, vol. 19, no. 9, pp. 587-593, 2008.

[69] N. Arpaia, C. Campbell, X. Fan et al., "Metabolites produced by commensal bacteria promote peripheral regulatory $\mathrm{T}$-cell generation," Nature, vol. 504, no. 7480, pp. 451-455, 2013.

[70] V. Braniste, M. Al-Asmakh, C. Kowal et al., "The gut microbiota influences blood-brain barrier permeability in mice," Science Translational Medicine, vol. 6, no. 263, article 263ra158, 2014.

[71] D. Erny, A. L. Hrabe de Angelis, D. Jaitin et al., "Host microbiota constantly control maturation and function of microglia in the cns," Nature Neuroscience, vol. 18, no. 7, pp. 965-977, 2015.

[72] K. M. Maslowski, A. T. Vieira, A. Ng et al., "Regulation of inflammatory responses by gut microbiota and chemoattractant receptor gpr43," Nature, vol. 461, no. 7268, pp. 12821286, 2009.

[73] A. Kadowaki, S. Miyake, R. Saga, A. Chiba, H. Mochizuki, and T. Yamamura, "Gut environment-induced intraepithelial autoreactive $\mathrm{CD}^{+} \mathrm{T}$ cells suppress central nervous system autoimmunity via LAG-3," Nature Communications, vol. 7, article 11639, 2016.

[74] M. C. Cénit, V. Matzaraki, E. F. Tigchelaar, and A. Zhernakova, "Rapidly expanding knowledge on the role of the gut microbiome in health and disease," Biochimica et Biophysica Acta (BBA) - Molecular Basis of Disease, vol. 1842, no. 10, pp. 1981-1992, 2014.

[75] The ENCODE Project Consortium, E. Birney, J. A. Stamatoyannopoulos et al., "Identification and analysis of functional elements in $1 \%$ of the human genome by the encode pilot project," Nature, vol. 447, no. 7146 , pp. 799816, 2007.

[76] J. F. Petrosino, S. Highlander, R. A. Luna, R. A. Gibbs, and J. Versalovic, "Metagenomic pyrosequencing and microbial identification," Clinical Chemistry, vol. 55, no. 5, pp. 856866, 2009.

[77] K. Chen and L. Pachter, "Bioinformatics for whole-genome shotgun sequencing of microbial communities," PLoS Computational Biology, vol. 1, no. 2, article e24, 2005.

[78] J. Ochoa-Repáraz and L. H. Kasper, "Gut microbiome and the risk factors in central nervous system autoimmunity," FEBS Letters, vol. 588, no. 22, pp. 4214-4222, 2014.

[79] Y. Wang and L. H. Kasper, "The role of microbiome in central nervous system disorders," Brain, Behavior, and Immunity, vol. 38, pp. 1-12, 2014.
[80] K. M. Telesford, W. Yan, J. Ochoa-Reparaz et al., "A commensal symbiotic factor derived from Bacteroides fragilis promotes human $\mathrm{CD}_{3} 9^{+} \mathrm{Foxp}^{+} \mathrm{T}$ cells and Treg function," Gut Microbes, vol. 6, no. 4, pp. 234242, 2015.

[81] R. B. Clark, J. L. Cervantes, M. W. Maciejewski et al., "Serine lipids of porphyromonas gingivalis are human and mouse toll-like receptor 2 ligands," Infection and Immunity, vol. 81, no. 9, pp. 3479-3489, 2013.

[82] P. Dilokthornsakul, R. J. Valuck, K. V. Nair, J. R. Corboy, R. R. Allen, and J. D. Campbell, "Multiple sclerosis prevalence in the United States commercially insured population," Neurology, vol. 86, no. 11, pp. 1014-1021, 2016.

[83] E. Kingwell, J. J. Marriott, N. Jette et al., "Incidence and prevalence of multiple sclerosis in Europe: a systematic review," BMC Neurology, vol. 13, no. 1, p. 128, 2013.

[84] C. A. Dendrou, L. Fugger, and M. A. Friese, "Immunopathology of multiple sclerosis," Nature Reviews Immunology, vol. 15, no. 9, pp. 545-558, 2015.

[85] C. $\mathrm{Gu}$, "Kir4.1: $\mathrm{K}^{+}$channel illusion or reality in the autoimmune pathogenesis of multiple sclerosis," Frontiers in Molecular Neuroscience, vol. 9, p. 90, 2016.

[86] J. M. Fletcher, S. J. Lalor, C. M. Sweeney, N. Tubridy, and K. H. Mills, "T cells in multiple sclerosis and experimental autoimmune encephalomyelitis," Clinical \& Experimental Immunology, vol. 162, no. 1, pp. 1-11, 2010.

[87] X. Fan, C. Lin, J. Han, X. Jiang, J. Zhu, and T. Jin, "Follicular helper $\mathrm{CD}^{+} \mathrm{T}$ cells in human neuroautoimmune diseases and their animal models," Mediators of Inflammation, vol. 2015, Article ID 638968, 11 pages, 2015.

[88] P. K. Stys, G. W. Zamponi, J. van Minnen, and J. J. Geurts, "Will the real multiple sclerosis please stand up?," Nature Reviews Neuroscience, vol. 13, no. 7, pp. 507-514, 2012.

[89] T. Kuhlmann, S. Ludwin, A. Prat, J. Antel, W. Bruck, and H. Lassmann, "An updated histological classification system for multiple sclerosis lesions," Acta Neuropathologica, vol. 133, no. 1, pp. 13-24, 2017.

[90] M. Rangachari, S. M. Kerfoot, N. Arbour, and J. I. Alvarez, "Editorial: Lymphocytes in MS and EAE: more than just a CD4 ${ }^{+}$world," Frontiers in Immunology, vol. 8, p. 133, 2017.

[91] A. V. Chervonsky, "Influence of microbial environment on autoimmunity," Nature Immunology, vol. 11, no. 1, pp. 2835, 2010.

[92] V. Rothhammer and F. J. Quintana, "Environmental control of autoimmune inflammation in the central nervous system," Current Opinion in Immunology, vol. 43, pp. 4653, 2016

[93] V. V. Bashinskaya, O. G. Kulakova, A. N. Boyko, A. V. Favorov, and O. O. Favorova, "A review of genome-wide association studies for multiple sclerosis: classical and hypothesis-driven approaches," Human Genetics, vol. 134, no. 11-12, pp. 1143-1162, 2015.

[94] A. Compston and A. Coles, "Multiple sclerosis," The Lancet, vol. 372, no. 9648, pp. 1502-1517, 2008.

[95] C. Tao, S. Simpson, I. van der Mei et al., "Higher latitude is significantly associated with an earlier age of disease onset in multiple sclerosis," Journal of Neurology, Neurosurgery \& Psychiatry, vol. 87, no. 12, pp. 1343-1349, 2016.

[96] W. H. Brooks, C. Le Dantec, J. O. Pers, P. Youinou, and Y. Renaudineau, "Epigenetics and autoimmunity," Journal of Autoimmunity, vol. 34, no. 3, pp. J207-J219, 2010. 
[97] I. Selmaj, M. P. Mycko, C. S. Raine, and K. W. Selmaj, “The role of exosomes in cns inflammation and their involvement in multiple sclerosis," Journal of Neuroimmunology, vol. 306, pp. 1-10, 2017.

[98] C. I. Kucukali, M. Kurtuncu, A. Coban, M. Cebi, and E. Tuzun, "Epigenetics of multiple sclerosis: an updated review," NeuroMolecular Medicine, vol. 17, no. 2, pp. 83-96, 2015.

[99] S. Simpson Jr., B. V. Taylor, and I. van der Mei, "The role of epidemiology in ms research: past successes, current challenges and future potential," Multiple Sclerosis Journal, vol. 21, no. 8, pp. 969-977, 2015.

[100] A.-K. Fleck, D. Schuppan, H. Wiendl, and L. Klotz, "Gutcns-axis as possibility to modulate inflammatory disease activity-implications for multiple sclerosis," International Journal of Molecular Sciences, vol. 18, no. 12, article 1526, 2017.

[101] J. N. Brenton and M. D. Goldman, "A study of dietary modification: perceptions and attitudes of patients with multiple sclerosis," Multiple Sclerosis and Related Disorders, vol. 8, pp. 54-57, 2016.

[102] J. J. L. H. Kasper, "Digesting the emerging role for the gut microbiome in central nervous system demyelination," Multiple Sclerosis Journal, vol. 20, no. 12, pp. 1553-1559, 2014.

[103] N. P. Ly, A. Litonjua, D. R. Gold, and J. C. Celedon, "Gut microbiota, probiotics, and vitamin d: interrelated exposures influencing allergy, asthma, and obesity?," The Journal of Allergy and Clinical Immunology, vol. 127, no. 5, pp. 10871094, 2011.

[104] L. Biedermann, J. Zeitz, J. Mwinyi et al., "Smoking cessation induces profound changes in the composition of the intestinal microbiota in humans," PLoS One, vol. 8, no. 3, article e59260, 2013.

[105] V. Rothhammer, I. D. Mascanfroni, L. Bunse et al., "Type I interferons and microbial metabolites of tryptophan modulate astrocyte activity and central nervous system inflammation via the aryl hydrocarbon receptor," Nature Medicine, vol. 22, no. 6, pp. 586-597, 2016.

[106] A. E. Hoban, R. M. Stilling, F. J. Ryan et al., "Regulation of prefrontal cortex myelination by the microbiota," Translational Psychiatry, vol. 6, no. 4, article e774, 2016.

[107] L. V. Hooper, D. R. Littman, and A. J. Macpherson, "Interactions between the microbiota and the immune system," Science, vol. 336, no. 6086, pp. 1268-1273, 2012.

[108] Y. K. Lee, J. S. Menezes, Y. Umesaki, and S. K. Mazmanian, "Proinflammatory T-cell responses to gut microbiota promote experimental autoimmune encephalomyelitis," Proceedings of the National Academy of Sciences of the United States of America, vol. 108, Supplement 1, pp. 4615-4622, 2011.

[109] K. Berer, M. Mues, M. Koutrolos et al., "Commensal microbiota and myelin autoantigen cooperate to trigger autoimmune demyelination," Nature, vol. 479, no. 7374, pp. 538-541, 2011.

[110] H. Yokote, S. Miyake, J. L. Croxford, S. Oki, H. Mizusawa, and T. Yamamura, "Nkt cell-dependent amelioration of a mouse model of multiple sclerosis by altering gut flora," The American Journal of Pathology, vol. 173, no. 6, pp. 1714-1723, 2008.

[111] S. Lavasani, B. Dzhambazov, M. Nouri et al., "A novel probiotic mixture exerts a therapeutic effect on experimental autoimmune encephalomyelitis mediated by il-10 producing regulatory t cells," PLoS One, vol. 5, no. 2, article e9009, 2010.
[112] J. Ochoa-Reparaz, A. Rynda, M. A. Ascon et al., "IL-13 production by regulatory $\mathrm{T}$ cells protects against experimental autoimmune encephalomyelitis independently of autoantigen," The Journal of Immunology, vol. 181, no. 2, pp. 954968, 2008.

[113] J. Ezendam, A. de Klerk, E. R. Gremmer, and H. van Loveren, "Effects of Bifidobacterium animalis administered during lactation on allergic and autoimmune responses in rodents," Clinical \& Experimental Immunology, vol. 154, no. 3, pp. 424-431, 2008.

[114] J. Ochoa-Reparaz, D. W. Mielcarz, L. E. Ditrio et al., "Central nervous system demyelinating disease protection by the human commensal Bacteroides fragilis depends on polysaccharide a expression," The Journal of Immunology, vol. 185, no. 7, pp. 4101-4108, 2010.

[115] J. Ochoa-Reparaz, C. Riccardi, A. Rynda, S. Jun, G. Callis, and D. W. Pascual, "Regulatory $\mathrm{T}$ cell vaccination without autoantigen protects against experimental autoimmune encephalomyelitis," The Journal of Immunology, vol. 178, no. 3, pp. 1791-1799, 2007.

[116] S. B.-H. Yan Wang, M. Kiel, J. Telesford et al., "A commensal bacterial product elicits and modulates migratory capacity of $\mathrm{CD}_{39}{ }^{+} \mathrm{CD} 4 \mathrm{~T}$ regulatory subsets in the suppression of neuroinflammation," Gut Microbes, vol. 5, no. 4, pp. 552-561, 2014.

[117] J. L. Round and S. K. Mazmanian, "Inducible Foxp $3^{+}$regulatory T-cell development by a commensal bacterium of the intestinal microbiota," Proceedings of the National Academy of Sciences of the United States of America, vol. 107, no. 27, pp. 12204-12209, 2010.

[118] K. Takata, M. Kinoshita, T. Okuno et al., "The lactic acid bacterium Pediococcus acidilactici suppresses autoimmune encephalomyelitis by inducing IL-10-producing regulatory T cells," PLoS One, vol. 6, no. 11, article e27644, 2011.

[119] C. B. Maassen and E. Claassen, "Strain-dependent effects of probiotic lactobacilli on EAE autoimmunity," Vaccine, vol. 26, no. 17, pp. 2056-2057, 2008.

[120] A. Mangalam, S. K. Shahi, D. Luckey et al., "Human gutderived commensal bacteria suppress CNS inflammatory and demyelinating disease," Cell Reports, vol. 20, no. 6, pp. 1269-1277, 2017.

[121] K. N. Chitrala, H. Guan, N. P. Singh et al., "Cd44 deletion leading to attenuation of experimental autoimmune encephalomyelitis results from alterations in gut microbiome in mice," European Journal of Immunology, vol. 47, no. 7, pp. 1188-1199, 2017.

[122] S. Jun, J. Ochoa-Reparaz, D. Zlotkowska, T. Hoyt, and D. W. Pascual, "Bystander-mediated stimulation of proteolipid protein-specific regulatory $\mathrm{T}\left(\mathrm{T}_{\text {reg }}\right)$ cells confers protection against experimental autoimmune encephalomyelitis (EAE) via TGF- $\beta$," Journal of Neuroimmunology, vol. 245 , no. 1-2, pp. 39-47, 2012.

[123] S. Jun, W. Gilmore, G. Callis, A. Rynda, A. Haddad, and D. W. Pascual, "A live diarrheal vaccine imprints a Th2 cell bias and acts as an anti-inflammatory vaccine," The Journal of Immunology, vol. 175, no. 10, pp. 6733-6740, 2005.

[124] K. Atarashi, T. Tanoue, T. Shima et al., "Induction of colonic regulatory T cells by indigenous clostridium species," Science, vol. 331, no. 6015, pp. 337-341, 2011.

[125] K. Atarashi, T. Tanoue, K. Oshima et al., " $\mathrm{T}_{\text {reg }}$ induction by a rationally selected mixture of clostridia strains from the human microbiota," Nature, vol. 500, no. 7461, pp. 232236, 2013. 
[126] E. Cekanaviciute, B. B. Yoo, T. F. Runia et al., "Gut bacteria from multiple sclerosis patients modulate human $\mathrm{T}$ cells and exacerbate symptoms in mouse models," Proceedings of the National Academy of Sciences of the United States of America, vol. 114, no. 40, pp. 10713-10718, 2017.

[127] K. Berer, L. A. Gerdes, E. Cekanaviciute et al., "Gut microbiota from multiple sclerosis patients enables spontaneous autoimmune encephalomyelitis in mice," Proceedings of the National Academy of Sciences of the United States of America, vol. 114, no. 40, pp. 10719-10724, 2017.

[128] S. Jangi, R. Gandhi, L. M. Cox et al., "Alterations of the human gut microbiome in multiple sclerosis," Nature Communications, vol. 7, article 12015, 2016.

[129] M. Derrien, P. Van Baarlen, G. Hooiveld, E. Norin, M. Muller, and W. M. de Vos, "Modulation of mucosal immune response, tolerance, and proliferation in mice colonized by the mucin-degrader akkermansia muciniphila," Frontiers in Microbiology, vol. 2, p. 166, 2011.

[130] B. P. Ganesh, R. Klopfleisch, G. Loh, and M. Blaut, "Commensal Akkermansia muciniphila exacerbates gut inflammation in Salmonella Typhimurium-infected gnotobiotic mice," PLoS One, vol. 8, no. 9, article e74963, 2013.

[131] Y. Furusawa, Y. Obata, S. Fukuda et al., "Commensal microbe-derived butyrate induces the differentiation of colonic regulatory T cells," Nature, vol. 504, no. 7480, pp. 446-450, 2013.

[132] H. Tremlett, D. W. Fadrosh, A. A. Faruqi et al., "Gut microbiota in early pediatric multiple sclerosis: a case-control study," European Journal of Neurology, vol. 23, no. 8, pp. 1308-1321, 2016.

[133] H. Tremlett, D. W. Fadrosh, A. A. Faruqi et al., "Gut microbiota composition and relapse risk in pediatric MS: a pilot study," Journal of the Neurological Sciences, vol. 363, pp. 153-157, 2016.

[134] H. Tremlett, D. W. Fadrosh, A. A. Faruqi et al., "Associations between the gut microbiota and host immune markers in pediatric multiple sclerosis and controls," BMC Neurology, vol. 16, no. 1, p. 182, 2016.

[135] G. L. Hold, S. E. Pryde, V. J. Russell, E. Furrie, and H. J. Flint, "Assessment of microbial diversity in human colonic samples by $16 \mathrm{~s}$ rDNA sequence analysis," FEMS Microbiology Ecology, vol. 39, no. 1, pp. 33-39, 2002.

[136] J. M. Manson, M. Rauch, and M. S. Gilmore, "The commensal microbiology of the gastrointestinal tract," in GI Microbiota and Regulation of the Immune System, G. B. Huffnagle and M. C. Noverr, Eds., vol. 635 of Advances in Experimental Medicine and Biology, pp. 15-28, Springer, New York, NY, USA, 2008.

[137] B. A. Wilson, S. Miyake, S. Kim et al., "Dysbiosis in the gut microbiota of patients with multiple sclerosis, with a striking depletion of species belonging to clostridia Xiva and IV clusters," PLoS One, vol. 10, no. 9, article e0137429, 2015.

[138] B. L. Cantarel, E. Waubant, C. Chehoud et al., "Gut microbiota in multiple sclerosis," Journal of Investigative Medicine, vol. 63, no. 5, pp. 729-734, 2015.

[139] K. R. Rumah, J. Linden, V. A. Fischetti, and T. Vartanian, "Isolation of Clostridium perfringens type b in an individual at first clinical presentation of multiple sclerosis provides clues for environmental triggers of the disease," PLoS One, vol. 8, no. 10, article e76359, 2013.
[140] J. Chen, N. Chia, K. R. Kalari et al., "Multiple sclerosis patients have a distinct gut microbiota compared to healthy controls," Scientific Reports, vol. 6, no. 1, article 28484, 2016.

[141] E. H. Crost, L. E. Tailford, G. Le Gall, M. Fons, B. Henrissat, and N. Juge, "Utilisation of mucin glycans by the human gut symbiont Ruminococcus gnavus is strain-dependent," PLoS One, vol. 8, no. 10, article e76341, 2013.

[142] M. Schirmer, S. P. Smeekens, H. Vlamakis et al., "Linking the human gut microbiome to inflammatory cytokine production capacity," Cell, vol. 167, no. 4, pp. 1125-1136.e8, 2016.

[143] W. G. Branton, J. Q. Lu, M. G. Surette et al., "Brain microbiota disruption within inflammatory demyelinating lesions in multiple sclerosis," Scientific Reports, vol. 6, no. 1, article 37344, 2016.

[144] M. Kleinewietfeld, A. Manzel, J. Titze et al., "Sodium chloride drives autoimmune disease by the induction of pathogenic $\mathrm{T}_{\mathrm{H}} 17$ cells," Nature, vol. 496, no. 7446, pp. 518-522, 2013.

[145] V. Farrokhi, R. Nemati, F. C. Nichols et al., "Bacterial lipodipeptide, lipid 654, is a microbiome-associated biomarker for multiple sclerosis," Clinical \& Translational Immunology, vol. 2, no. 11, article e8, 2013.

[146] Q. Yang, C. Zheng, J. Cao et al., "Spermidine alleviates experimental autoimmune encephalomyelitis through inducing inhibitory macrophages," Cell Death \& Differentiation, vol. 23, no. 11, pp. 1850-1861, 2016.

[147] L. Piccio, J. L. Stark, and A. H. Cross, "Chronic calorie restriction attenuates experimental autoimmune encephalomyelitis," Journal of Leukocyte Biology, vol. 84, no. 4, pp. 940-948, 2008.

[148] D. Tripathy, P. Mohanty, S. Dhindsa et al., "Elevation of free fatty acids induces inflammation and impairs vascular reactivity in healthy subjects," Diabetes, vol. 52, no. 12, pp. 2882-2887, 2003.

[149] H. K. Kwon, G. C. Kim, Y. Kim et al., "Amelioration of experimental autoimmune encephalomyelitis by probiotic mixture is mediated by a shift in $\mathrm{t}$ helper cell immune response," Clinical Immunology, vol. 146, no. 3, pp. 217227, 2013.

[150] G. L. V. de Oliveira, A. Z. Leite, B. S. Higuchi, M. I. Gonzaga, and V. S. Mariano, "Intestinal dysbiosis and probiotic applications in autoimmune diseases," Immunology, vol. 152, no. 1, pp. 1-12, 2017.

[151] S. Jorg, J. Kissel, A. Manzel et al., "High salt drives Th17 responses in experimental autoimmune encephalomyelitis without impacting myeloid dendritic cells," Experimental Neurology, vol. 279, pp. 212-222, 2016.

[152] S. Hucke, M. Eschborn, M. Liebmann et al., "Sodium chloride promotes pro-inflammatory macrophage polarization thereby aggravating cns autoimmunity," Journal of Autoimmunity, vol. 67, pp. 90-101, 2016.

[153] A. Haghikia, S. Jorg, A. Duscha et al., "Dietary fatty acids directly impact central nervous system autoimmunity via the small intestine," Immunity, vol. 44, no. 4, pp. 951-953, 2016.

[154] M. Farez, M. Fiol, M. Gaitán, F. Quintana, and J. Correale, "Sodium intake is associated with increased disease activity in multiple sclerosis," Journal of Neurology, Neurosurgery \& Psychiatry, vol. 86, no. 1, pp. 26-31, 2015.

[155] C. Mattozzi, G. Paolino, M. Salvi et al., "Peripheral blood regulatory $\mathrm{T}$ cell measurements correlate with serum vitamin $\mathrm{D}$ level in patients with psoriasis," European Review for 
Medical and Pharmacological Sciences, vol. 20, no. 9, pp. 1675-1679, 2016.

[156] S. W. Kang, S. H. Kim, N. Lee et al., "1,25-dihyroxyvitamin $\mathrm{D}_{3}$ promotes foxp3 expression via binding to vitamin $\mathrm{d}$ response elements in its conserved noncoding sequence region," The Journal of Immunology, vol. 188, no. 11, pp. 5276-5282, 2012.

[157] J. Ochoa-Reparaz, D. W. Mielcarz, S. Haque-Begum, and L. H. Kasper, "Induction of a regulatory b cell population in experimental allergic encephalomyelitis by alteration of the gut commensal microflora," Gut Microbes, vol. 1, no. 2, pp. 103-108, 2010.

[158] S. L. K. E. Colpitts, "A bidirectional association between the gut microbiota and CNS disease in a biphasic murine model of multiple sclerosis," Gut Microbes, vol. 8, no. 6, pp. 561$573,2017$.

[159] W. J. van den Hoogen, J. D. Laman, and B. A. 't Hart, "Modulation of multiple sclerosis and its animal model experimental autoimmune encephalomyelitis by food and gut microbiota," Frontiers in Immunology, vol. 8, article 1081, 2017.

[160] L. Dethlefsen and D. A. Relman, "Incomplete recovery and individualized responses of the human distal gut microbiota to repeated antibiotic perturbation," Proceedings of the National Academy of Sciences of the United States of America, vol. 108, Supplement 1, pp. 4554-4561, 2011.

[161] K. R. Rumah, T. K. Vartanian, and V. A. Fischetti, "Oral multiple sclerosis drugs inhibit the in vitro growth of epsilon toxin producing gut bacterium, Clostridium perfringens," Frontiers in Cellular and Infection Microbiology, vol. 7, p. 11, 2017.

[162] P. Bron, M. Kleerebezem, R. Brummer et al., "Can probiotics modulate human disease by impacting intestinal barrier function?," British Journal of Nutrition, vol. 117, no. 01, pp. 93-107, 2017.

[163] M. G. Gareau, P. M. Sherman, and W. A. Walker, "Probiotics and the gut microbiota in intestinal health and disease," Nature Reviews Gastroenterology \& Hepatology, vol. 7, no. 9, pp. 503-514, 2010.

[164] H. Wang, I. S. Lee, C. Braun, and P. Enck, "Effect of probiotics on central nervous system functions in animals and humans: a systematic review," Journal of Neurogastroenterology and Motility, vol. 22, no. 4, pp. 589-605, 2016.

[165] J. Ochoa-Reparaz, D. W. Mielcarz, Y. Wang et al., "A polysaccharide from the human commensal Bacteroides fragilis protects against CNS demyelinating disease," Mucosal Immunology, vol. 3, no. 5, pp. 487-495, 2010.

[166] J. Ezendam and H. van Loveren, "Lactobacillus casei shirota administered during lactation increases the duration of autoimmunity in rats and enhances lung inflammation in mice," The British Journal of Nutrition, vol. 99, no. 01, pp. 83-90, 2008.

[167] K. Takata, T. Tomita, T. Okuno et al., "Dietary yeasts reduce inflammation in central nerve system via microflora," Annals of Clinical Translational Neurology, vol. 2, no. 1, pp. 56-66, 2015.

[168] L. Shapira, S. Ayalon, and T. Brenner, "Effects of Porphyromonas gingivalis on the central nervous system: activation of glial cells and exacerbation of experimental autoimmune encephalomyelitis," Journal of Periodontology, vol. 73, no. 5, pp. 511-516, 2002.
[169] F. C. Nichols, W. J. Housley, C. A. O'Conor, T. Manning, S. Wu, and R. B. Clark, "Unique lipids from a common human bacterium represent a new class of toll-like receptor 2 ligands capable of enhancing autoimmunity," The American Journal of Pathology, vol. 175, no. 6, pp. 2430-2438, 2009.

[170] R. M. Rezende, R. P. Oliveira, S. R. Medeiros et al., "Hsp65producing lactococcus lactis prevents experimental autoimmune encephalomyelitis in mice by inducing CD4+LAP+ regulatory t cells," Journal of Autoimmunity, vol. 40, pp. 45-57, 2013.

[171] M. Q. Xu, H. L. Cao, W. Q. Wang et al., "Fecal microbiota transplantation broadening Its application beyond intestinal disorders," World Journal of Gastroenterology, vol. 21, no. 1, pp. 102-111, 2015.

[172] M. Kasubuchi, S. Hasegawa, T. Hiramatsu, A. Ichimura, and I. Kimura, "Dietary gut microbial metabolites, short-chain fatty acids, and host metabolic regulation," Nutrients, vol. 7, pp. 2839-2849, 2015.

[173] M. Adamczyk-Sowa, A. Medrek, P. Madej, W. Michlicka, and P. Dobrakowski, "Does the gut microbiota influence immunity and inflammation in multiple sclerosis pathophysiology?," Journal of Immunology Research, vol. 2017, Article ID 7904821, 14 pages, 2017.

[174] H. H. Choi and Y. S. Cho, "Fecal microbiota transplantation: current applications, effectiveness, and future perspectives," Clinical endoscopy, vol. 49, no. 3, pp. 257-265, 2016.

[175] T. Borody, S. Leis, J. Campbell, and M. Torres, "Fecal microbiota transplantation (FMT) in multiple sclerosis (MS)," The American Journal of Gastroenterology, vol. s352, p. 106, 2011.

[176] C. Terrazas, J. de Dios Ruiz-Rosado, S. A. Amici et al., "Helminth-induced $1 y 6 c$ hi monocyte-derived alternatively activated macrophages suppress experimental autoimmune encephalomyelitis," Scientific Reports, vol. 7, article 40814, 2017.

[177] J. Correale and M. Farez, "Association between parasite infection and immune responses in multiple sclerosis," Annals of Neurology, vol. 61, no. 2, pp. 97-108, 2007.

[178] J. Correale and M. F. Farez, "The impact of parasite infections on the course of multiple sclerosis," Journal of Neuroimmunology, vol. 233, no. 1-2, pp. 6-11, 2011.

[179] R. A. Liddle, "Parkinson's disease from the gut," Brain Research, 2018.

[180] G. Winter and R. A. Hart, "Gut microbiome and depression: what we know and what we need to know," Reviews in the Neurosciences, no. 0, 2018.

[181] A. Lionnet, L. Leclair-Visonneau, M. Neunlist et al., "Does Parkinson's disease start in the gut?," Acta Neuropathologica, vol. 135, no. 1, pp. 1-12, 2018.

[182] J. Ochoa-Reparaz, T. O. Kirby, and L. H. Kasper, “The gut microbiome and multiple sclerosis," Cold Spring Harbor Perspectives in Medicine, 2018.

[183] S. N. Freedman, S. K. Shahi, and A. K. Mangalam, "The "gut feeling": breaking down the role of gut microbiome in multiple sclerosis," Neurotherapeutics, vol. 15, no. 1, pp. 109-125, 2018.

[184] Y. Wang, K. M. Telesford, J. Ochoa-Reparaz et al., “An intestinal commensal symbiosis factor controls neuroinflammation via tlr2-mediated cd39 signalling," Nature Communications, vol. 5, article 4432, 2014. 


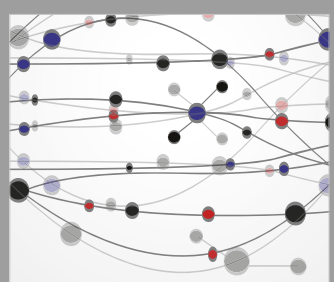

The Scientific World Journal
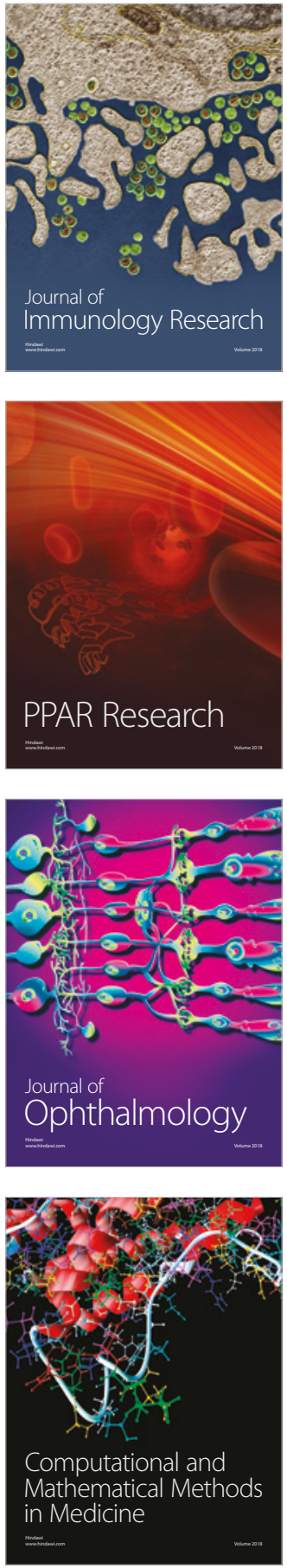

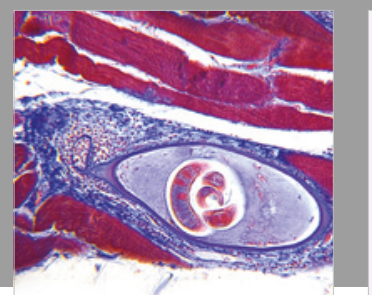

Gastroenterology Research and Practice

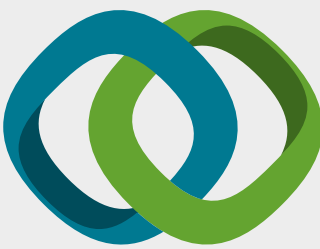

\section{Hindawi}

Submit your manuscripts at

www.hindawi.com
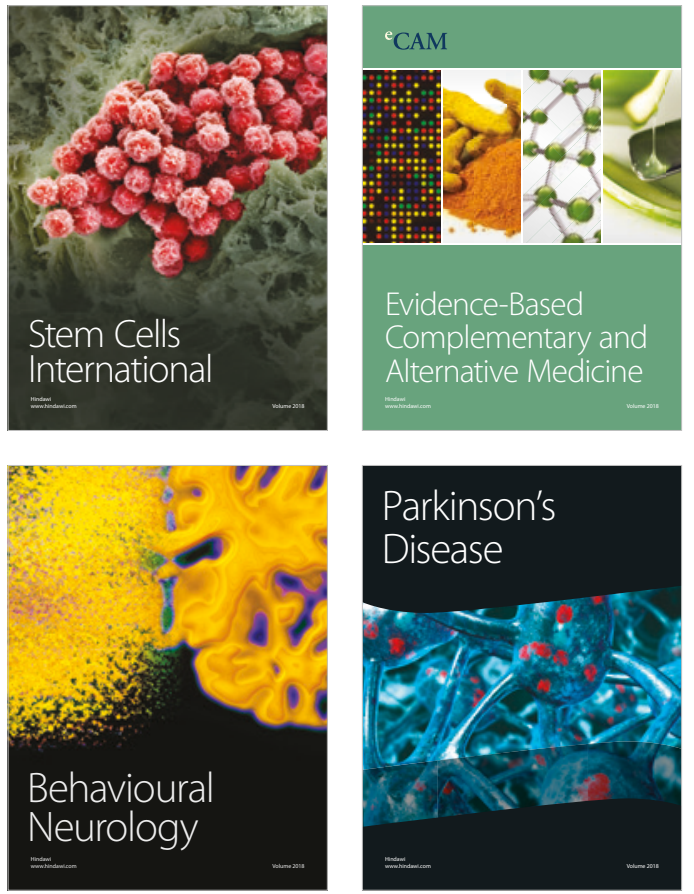

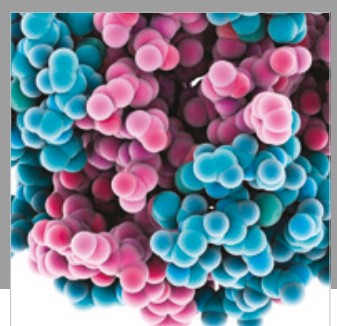

ournal of

Diabetes Research

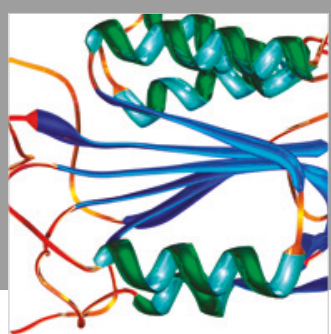

Disease Markers
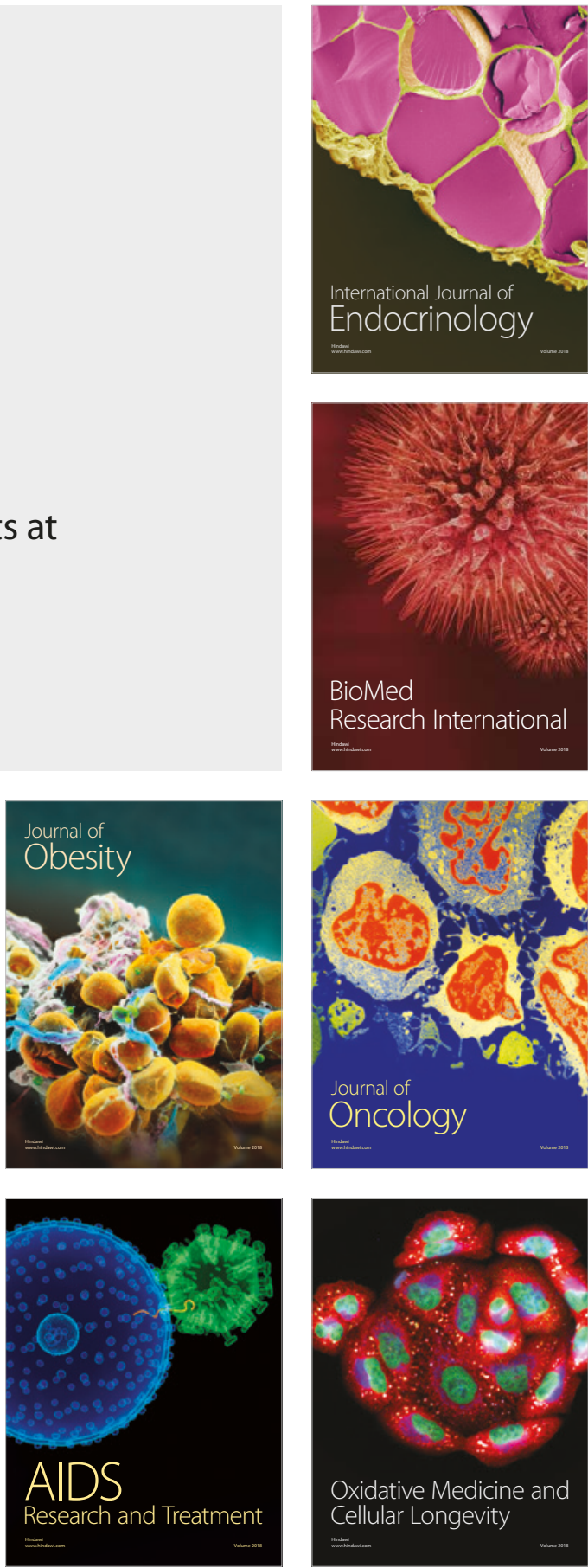